\title{
EXPLOITING FUTURE SETTLEMENTS: \\ A Signalling Model of Most-Favored-Nation Clauses IN SETTLEMENT BARGAINING
}

by

Andrew F. Daughety and Jennifer F. Reinganum

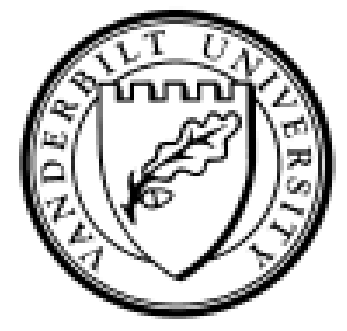

Working Paper No. 02-W21

August 2002

Revised October 2002

DEPARTMENT OF ECONOMICS

VANDERBILT UNIVERSITY

NASHVILLE, TN 37235

www.vanderbilt.edu/econ 


\author{
Exploiting Future Settlements: \\ A Signaling Model of Most-Favored-Nation Clauses in Settlement Bargaining \\ Andrew F. Daughety* \\ Jennifer F. Reinganum* \\ Department of Economics \\ and Law School \\ Vanderbilt University \\ Nashville, TN 37235 \\ andrew.f.daughety@vanderbilt.edu \\ jennifer.f.reinganum@vanderbilt.edu
}

August 2002

Last Revised: October 2002

* This paper was inspired by Spier (forthcoming, RAND Journal), and grew out of our discussion of her analysis at the NBER Summer Law and Economics Workshop, 2002. We thank Kathy Spier for comments on an earlier draft. 
Exploiting Future Settlements:

A Signaling Model of Most-Favored-Nation Clauses in Settlement Bargaining

Andrew F. Daughety

Jennifer F. Reinganum

\begin{abstract}
"Most-favored-nation" (hereafter, MFN) clauses have been used in analyses of international trade, durable goods monopoly pricing, and franchise contracting to address a repeat player's timeinconsistency problem. Recent work by Spier (forthcoming and 2002) has extended this perspective to the settlements of litigation by (for example) one defendant with a collection of plaintiffs.

We examine a different motivation for the use of MFNs in settlement bargaining. We argue that a non-repeat player can use an MFN to extend her reach into subsequent bargaining games. That is, an early-bargaining plaintiff can use an MFN to modify the subsequent bargaining game between the defendant and a later-bargaining plaintiff in a manner that improves the early plaintiff's payoff. Moreover, we will identify two routes through which this improvement is achieved. The obvious route is that, if the MFN is triggered by the later settlement, the early plaintiff receives an additional payment. The less obvious route is that the early plaintiff's incentives for informationrevelation can be enhanced by the potential for a future payment, so that the defendant can resort to trial on a less-frequent basis. Using a signaling model, we find that the repeat player (the defendant) is indifferent about the MFN, while the later plaintiff is always worse off when an MFN constrains her settlement bargaining with the defendant. Although MFNs can never provide a Pareto improvement in this model, we demonstrate that plausible circumstances exist under which total surplus is increased by an MFN.
\end{abstract}




\section{Introduction}

"Most-favored-nation" (hereafter, MFN) clauses have been used in a variety of contexts. In the context of international trade, a country might grant MFN status to another country, thereby promising to trade with that country on terms no worse than those enjoyed by any of the granting country's other trading partners. In the industrial organization context, a durable-goods monopolist might promise its buyers (or a franchisor might promise its franchisees) that, subsequent to concluding the instant deal, no other buyer (or franchisee) will obtain more favorable terms, unless those terms are retroactively extended to the previous buyers (or franchisees). In the context of settlement of litigation, which will be our primary interest, MFNs promise early-settling plaintiffs that later-settling plaintiffs will not obtain more favorable terms, unless those terms are retroactively extended to the early settlers. Such clauses have been employed in settlements associated with (among others) copyright infringement, bankruptcy proceedings, allegations of price-fixing and of racial discrimination, and claims by the states for restitution. ${ }^{1}$

An interesting proposed explanation for the use of MFN clauses is based on the recognition that these situations involve a repeat player who interacts with a collection of one-shot players over time. In this case, the repeat player can suffer from a problem of time inconsistency. The durablegoods monopolist, having sold some units at a relatively high price to those buyers with relatively

${ }^{1}$ In the context of bankruptcy, the creditors are the plaintiffs; see Sage and Bennett (2001). Antitrust actions involving the airlines (see In re Domestic Air Transportation Antitrust Litigation, 148 F.R.D. 297) and manufacturers (see, for example, In re Corrugated Container Antitrust Litigation, 753 F.2d 137 and Cintech Industrial Coatings, 85 F.3d 1198) have involved settlements with MFN clauses. Recently a U.S. District Court gave preliminary approval to a proposed settlement in a Title VII racial discrimination suit against Coca-Cola (see Civil Action No. 1:98-CV3679-RWS in 133 F. Supp. 2d 1364). Spier (forthcoming, and 2002) discusses examples drawn from antitrust (see In re Chicken Antitrust, 560 F. Supp. 943 and In re Vitamins Antitrust, 342 U.S. App. D.C. 26), copyright infringement (the recent settlements in the MP3.com case) and the settlements by Mississippi, Florida and Texas in the tobacco cases (see http://www.library.ucsf.edu/tobacco/litigation/). 
high willingness-to-pay, is tempted to cut the price in the next period in order to sell to buyers with a somewhat lower willingness-to-pay (Coase, 1972, and Bulow, 1982). A franchisor, having concluded a contract with one franchisee, is tempted to offer more favorable terms to another franchisor whose market will overlap somewhat with that of the first franchisee. This encroachment explains the need to offer more favorable terms (see, for example, McAfee and Schwartz, 1994). A defendant, having concluded a settlement with relatively low-damaged plaintiffs, is tempted to offer a higher settlement to the remaining plaintiffs who (having rejected the first offer) can be inferred to have relatively high damages (Spier, forthcoming). In all of these cases, rational anticipation of more-favorable terms in the future interferes with the repeat player's ability to conclude the early deals at his preferred terms.

In several recent papers, scholars have carefully demonstrated how the use of MFN clauses can solve the repeat player's time inconsistency problem. In the international trade context, Choi (1995) argues that an importing country has a time inconsistency problem of the following sort. Without an MFN, optimal import tariffs chosen after firms in exporting countries have chosen their technologies will be discriminatory (adverse to the low-cost firm); this undermines the incentives for exporters to choose low-cost technologies, which in turn increases the imported good's price. An MFN allows the importing country to commit to non-discriminatory tariffs, leading to more efficient technological choice and therefore a lower price for the imported good. Butz (1990) shows that incorporating an MFN clause into the sale of a durable good allows a durable-goods monopolist to commit to the (one-shot) monopoly output; that is, to the output it would optimally choose if it could commit to a one-time choice of output. While this is clearly good from the perspective of the 
durable-goods monopolist, ${ }^{2}$ it reduces both consumers' surplus and total surplus. Marx and Shaffer (2001) examine non-discrimination clauses in intermediate-goods markets, with a special emphasis on franchisor-franchisee relationships. They find that an MFN enables the franchisor to offer a sequence of contracts which yields the same outcome as if the franchisor were able to commit to a single (observable) contract. The resulting prevailing contract terms maximize the joint surplus of the franchisor and its franchisees, thus internalizing the encroachment externalities that would result in lower final goods prices absent a commitment mechanism. Again, this is good from the perspective of the franchisor and its franchisees but, to the extent that the firm has market power in the provision of final goods (and assuming that both franchisees would operate in the absence of an $\mathrm{MFN}),{ }^{3}$ this raises the equilibrium price in the final goods market and reduces both consumers' and total surplus.

In a pair of companion papers, Spier (forthcoming, and 2002) demonstrates that a defendant being sued simultaneously by multiple plaintiffs can use an MFN clause to commit to a single takeit-or-leave it offer, much like in the context of a durable-goods monopolist. However, she finds that the implications for welfare are quite different in the settlement context. Like the durable-goods monopolist, the defendant always gains through the use of an MFN. However, Spier also identifies conditions under which: the MFN results in a Pareto improvement (that is, plaintiffs also gain or, in any event, do not lose) when an MFN is implemented; plaintiffs lose, but total surplus is still

${ }^{2}$ Levy (2000) shows that an MFN can reduce signaling distortions in a monopoly market for a new product. In his model a high quality goods producer can employ an MFN as a second source (that is, besides the price) of information for consumers.

3 Marx and Shaffer point out that an MFN can raise total surplus in the event that only a single franchisee would operate in the absence of this provision. 
increased by an MFN; and total surplus is reduced (and hence plaintiffs lose more than the defendant gains) by an MFN.

We examine a different motivation for the use of MFNs in settlement bargaining. We argue that a non-repeat player can use an MFN to extend her reach into subsequent bargaining games. That is, an early-bargaining plaintiff can use an MFN to modify the subsequent bargaining game between the defendant and a later-bargaining plaintiff in a manner that improves the early plaintiff's payoff. Moreover, we will identify two routes through which this improvement is achieved. The obvious route is that, if the MFN is triggered by the later settlement, the early plaintiff receives an additional payment. The less obvious route is that the early plaintiff's incentives for informationrevelation can be enhanced by the potential for a future payment, so that the defendant can resort to trial on a less-frequent basis. Using a signaling model, we find that the repeat player (the defendant) is indifferent about the MFN, while the later plaintiff is always worse off when an MFN constrains her settlement bargaining with the defendant. Although MFNs can never provide a Pareto improvement in this model, we demonstrate that plausible circumstances exist under which total surplus is increased by an MFN.

The motivation for the use of MFNs that we focus on in this paper is similar to that addressed in our recent work on the use of confidential settlements in sequential suits wherein two plaintiffs sue the same defendant. There we found that an early-bargaining plaintiff could use a confidential settlement to extract surplus from a later-bargaining plaintiff, using the defendant as a conduit. While the early plaintiff's payoff was always higher (and the later plaintiff's payoff was lower) under confidentiality, in some circumstances (Daughety and Reinganum, forthcoming) the gains were shared with the defendant, while in others (Daughety and Reinganum, 1999) the defendant, 
too, was worse off. Again, although confidential settlements did not provide a Pareto improvement, we identified circumstances under which total expected surplus was nevertheless increased (because expected trial costs were decreased) by confidentiality.

\section{$\underline{\text { Relationship to Previous Work on MFNs in Settlement Bargaining }}$}

Since the Spier (forthcoming, and 2002) papers are closest to the current paper, it is worth spending some time comparing and contrasting them. In Spier (forthcoming), there is a continuum of injured plaintiffs facing a single defendant. Each plaintiff's level of damages is drawn independently from a common distribution, and a plaintiff's damages are her private information. Settlement bargaining takes place over (at most) two periods, under the following extensive form. In the first period, the uninformed defendant makes a single offer to all plaintiffs (thus, this is a screening model). Each plaintiff decides whether to accept or reject the offer; a plaintiff who accepts receives the offered amount and is out of the game. Any plaintiff who rejects the first-period offer pays a "delay cost" (as does the defendant), and proceeds to the second period. In the second period, the defendant makes another offer to all remaining plaintiffs. Each remaining plaintiff decides whether to accept or reject the offer; a plaintiff who accepts receives the offered amount and is out of the game, while any plaintiff who rejects the second-period offer goes to trial. Note that each plaintiff can choose to settle in either period. This model is analyzed both with, and without, an MFN, where an MFN specifies that if the defendant settles in period 2 for a higher amount than the settlement in period 1 , he must rebate the difference to those plaintiffs with whom he settled in period 1. Spier shows that an MFN implements the full-commitment solution (a single, take-it-orleave-it offer). There are two margins of interest in this model. One margin involves the overall extent of settlement, while the other involves the timing of settlement. The full-commitment (and 
MFN) offer is accepted in the first period by all plaintiffs with damages below a critical level, denoted $\hat{x}$. By contrast, without an MFN the defendant makes an increasing sequence of offers; some plaintiffs settle in each of the two periods, and settlement occurs for all plaintiffs with damages below a critical level denoted $\tilde{\mathrm{x}}$.

When all litigants can settle in either period, the use of the MFN eliminates delay costs that arise in equilibrium without an MFN. Spier shows that the MFN increases (leaves unchanged, decreases) overall settlement if the density function is increasing (constant, decreasing) at $\tilde{x}$. An MFN increases expected total trial costs only if the overall extent of settlement falls enough that increased litigation costs offset saved delay costs. Plaintiff welfare also pivots on this feature of the density function: plaintiffs are better off (the same, worse off) under an MFN if the density function is increasing (constant, decreasing) at $\tilde{\mathrm{x}}$. The defendant is better off with an MFN (since it implements his full-commitment outcome), so an MFN provides a Pareto improvement if the density function is non-decreasing at $\tilde{\mathrm{x}}$.

This model and motivation seem to represent well situations wherein all plaintiffs are present at the same time and negotiations proceed on a multilateral basis, and when strategic delay can be expected to contribute substantially to private, and social, costs. This can (but need not) occur when there is some precipitating event that launches a collection of suits; for instance, a successful government antitrust suit will be followed by a number of private suits for damages, and a bankruptcy will trigger action by all the creditors. In the vitamins case, the Department of Justice obtained guilty pleas from several manufacturers, which then led to the filing of approximately 49 private law suits for damages within three months (see Schlosser, 2001, and In re Vitamins Antitrust, 342 U.S. App. D.C. 26). In the MP3.com copyright infringement case, MP3.com was sued 
(essentially simultaneously) by five major record labels for unauthorized distribution of music (see Spier, forthcoming and 2002, for details). The proposed class-action settlement of a Title VII racial discrimination suit involving Coca-Cola cited earlier also seems to fit this model; an MFN is used to encourage plaintiffs to opt-in to the class settlement rather than opt-out and settle/litigate on their own.

However, an alternative extensive form, which envisions plaintiffs bargaining bilaterally with the defendant, would seem to be a better representation of some cases. For example, the lawsuits by the states in the tobacco cases were filed over a four-year period as legislatures and political decision-makers wrangled over whether and how to proceed. Mississippi was the first state to pursue a theory of restitution, claiming that the tobacco companies should pay past health-care expenditures made by the state on behalf of smokers. They filed their case in May, 1994, and included an MFN provision in their settlement with the tobacco companies, which was concluded in July, 1997. Florida filed in February, 1995 and settled (with an MFN) in August, 1997; Texas filed in March, 1996 and settled (with an MFN) in January, 1998. All these MFNs were triggered by the Minnesota settlement in May, 1998 (they had filed in August, 1994). This was against a backdrop of industry-proposed federal legislation which died in the Senate in June, 1998 (see Viscusi, 2002). After the federal approach failed, the remaining forty-six states were included in the Master Settlement Agreement (proposed in November, 1998) which is generally viewed as providing less favorable conditions than Mississippi, Florida, Texas and Minnesota already enjoyed (LaFrance, 2000).

In the case In re: Domestic Air Transportation Antitrust Litigation (148 F.R.D. 297), the class of consumer-plaintiffs is the repeat player, and the airline-defendants are non-repeat players. 
In June, 1990, a (would-be) class of consumer-plaintiffs filed suit against seven major airlines (Northwest, TWA, American, Delta, United, USAir and Continental) and the Airline Tariff Publishing Company (ATPCO), alleging that these companies conspired, through the use of ATPCO's computerized fare system, to fix the prices of passenger air tickets. Class certification was sought by the plaintiffs and opposed by the defendants. In May, 1991, prior to class certification, Northwest settled with the pending class. Included in its settlement was an MFN clause, and an agreement to withdraw its objection to class certification. TWA settled in June 1992 on "substantially the same terms (148 F.R.D. 297 at 310)," and the Court preliminarily approved these settlements in September, 1991. In June, 1992, American, Delta, United, USAir and ATPCO reached a proposed settlement with the plaintiff class, and Continental followed a week later. The pattern of settlement suggests that, early in the litigation process, the plaintiff class and some defendants were engaged in bilateral negotiations. ${ }^{4}$ Note that, in both the airline and Cintech (see footnote 4) cases, the record indicates that it was the non-repeat player who demanded an MFN, not the repeat player.

In this paper, we examine sequential bilateral bargaining and we also assume that the

${ }^{4}$ As another example of (largely sequential) bilateral negotiations in an antitrust setting, we briefly discuss the Cintech case cited earlier. On March 12, 1992, a class of customer-plaintiffs sued eight manufacturers of steel pails, alleging price-fixing. One defendant settled immediately and another filed for bankruptcy. Defendant Central Can began settlement negotiations and settled within three months, with an MFN clause, as did yet another defendant. Following extensive discovery, two more defendants settled in April, 1993, on terms similar to those of Central Can (including an MFN clause). On April 14, 1994, the Court granted summary judgment to defendant Prospect, and on June 27, 1994, the Court approved plaintiff's motion to dismiss their case against Cleveland Steel (as they had decided there was insufficient evidence to proceed). Central Can immediately moved for enforcement of its MFN clause, arguing that the plaintiffs' dismissal of their suit against Cleveland Steel constituted settlement on more favorable terms, and thus Central Can was entitled to a complete refund. The District Court denied this motion, on the basis that this event did not trigger the MFN; this was affirmed by the U.S. $6^{\text {th }}$ Circuit Court of Appeals. 
informed plaintiffs make the demands; thus, our game involves a sequence of signaling subgames. Furthermore, while Spier employs a continuum of plaintiffs (and thereby guarantees that some fraction will accept the first offer), we focus on the case of two plaintiffs, so none, one or both may end up at trial. This modeling difference is driven by the desire to analyze different strategic influences. With a continuum of plaintiffs, delay is the strategic focus and inter-plaintiff interaction is suppressed, while in our analysis, inter-plaintiff strategic considerations are highlighted and consideration of strategic delay is suppressed. In our first period, the early plaintiff makes a settlement demand, possibly incorporating an MFN. If the defendant rejects the demand, the case goes to trial and the early plaintiff is out of the game; the second period commences without an MFN potentially constraining bargaining. On the other hand, if the defendant accepts the first plaintiff's demand and an MFN was included, then second-period bargaining will be (potentially) constrained by the MFN. In the second period the later plaintiff makes a settlement demand, which the defendant either rejects or accepts. If this demand is rejected, the later plaintiff and the defendant go to trial and the game is over. If this demand is accepted, then the later plaintiff receives the amount she demanded. Moreover, if this accepted demand exceeds that at which the early plaintiff settled (and settlement included an MFN), then the early plaintiff receives a supplementary payment equal to the difference in the settlement amounts.

Although Spier (2002) mostly considers a two-type version of the model developed in Spier (forthcoming), with a greater emphasis on the legal issues and related scholarship, she briefly considers therein a complete-information version of the sequential bargaining model in which 
plaintiffs make the demands. ${ }^{5}$ Despite the simplicity of this model, it does yield some of the features of the asymmetric information version we consider below. For instance, it identifies the way in which the early-plaintiff's settlement amount constrains (under an MFN) the feasible demands of the later plaintiff, and it shows that some later cases that would otherwise have settled must go to trial under an MFN. However, because settlement in a complete information analysis occurs either with probability one or with probability zero, the use of an MFN can only raise expected total trial costs (all cases settle for sure without an MFN, but some can fail to settle with an MFN).

Under asymmetric information, we obtain a much more nuanced picture of how an MFN affects the likelihood of settlement in the early and later cases. In particular, some later plaintiff types are more likely to settle (in equilibrium), while others are less likely to do so, under an MFN. We identify plausible circumstances under which the overall likelihood that the later case settles is increased by an MFN. Similarly, we find that (under these same circumstances) every early plaintiff type is more likely to settle under an MFN. In these circumstances, the prospect of a future payoff weakens a plaintiff's incentives to mimic a higher-damaged type, and thus the defendant need not be as skeptical (i.e., he can reject a given demand with lower probability). We also find that the defendant's welfare is the same with or without an MFN, while the later plaintiff's welfare is lower for those types who are constrained by an MFN. Thus in the sequential signaling model, an MFN will never provide a Pareto improvement but will, under plausible circumstances, reduce expected total trial costs.

${ }^{5}$ Other papers using complete information models to examine sequential bargaining include Cooper and Fries (1991) and Nielson and Winter (1994), who argue that a seller can use MFNs to extract surplus from buyers. 


\section{Plan of the Paper}

In Section 2, we briefly describe the two-stage game and provide the basic notation. Section 3 considers the benchmark game when there is no MFN while Section 4 reconsiders this game when an MFN has been incorporated into the first-stage settlement. Section 5 then addresses welfare considerations and conditions under which an MFN would be included in a settlement. Section 6 contrasts our results with those of Spier and uses this comparison to discuss issues relevant to judicial review of settlement agreements with MFN clauses. An Appendix provides proofs of the propositions and relevant properties of our model; some derivations are included in the main text so as to facilitate exposition.

\section{Model Structure}

A defendant, $\mathrm{D}$, faces a sequence of plaintiffs, $\mathrm{P}_{1}$ and $\mathrm{P}_{2}$. As in Spier (forthcoming, and 2002), $P_{i}$ 's expected damages that would arise from a trial are denoted $x_{i}$, and they follow a density $\mathrm{f}(\bullet)$ which is everywhere positive on its support; we assume a compact support for the density: $\mathrm{x}$ $\in[\underline{\mathrm{x}}, \overline{\mathrm{x}}]$. There are no costs of negotiation, but $\mathrm{D}$ incurs a court cost, $\mathrm{k}^{\mathrm{D}}$, if there is a trial (for each trial), and each $\mathrm{P}_{\mathrm{i}}$ incurs a court cost, $\mathrm{k}^{\mathrm{P}}$, if she goes to trial against $\mathrm{D}$; for convenience, let $\mathrm{K} \equiv \mathrm{k}^{\mathrm{P}}$ $+k^{D}$. Moreover we assume $\underline{x}-k^{P}>0$, so that it is credible for $P_{i}$ to threaten to take $D$ to trial. Each $\mathrm{P}_{\mathrm{i}}$ 's level of expected damages is private information for that plaintiff, and we assume that (from the perspective of the other plaintiff and D) $\mathrm{x}_{1}$ and $\mathrm{x}_{2}$ are independent and identically distributed random variables.

The game is comprised of two stages and the sequence of actions is as follows. In stage one, $\mathrm{P}_{1}$ makes a demand $\mathrm{S}_{1}$, which $\mathrm{D}$ then accepts or rejects. If $\mathrm{D}$ accepts the demand, he pays $\mathrm{P}_{1}$ the 
amount $\mathrm{S}_{1}$, while if he rejects the demand $\mathrm{D}$ and $\mathrm{P}_{1}$ go to trial, $\mathrm{P}_{1}$ is awarded $\mathrm{x}_{1}$ (i.e., this is revealed at trial), D pays this amount and each litigant then pays their respective court costs. Stage 2 repeats the preceding scenario, but now with plaintiff $\mathrm{P}_{2}$ making demand $\mathrm{S}_{2}$ of $\mathrm{D}$. Should $\mathrm{S}_{2}$ exceed $\mathrm{S}_{1}$, and should D accept $S_{2}$, then D pays $S_{2}$ to $P_{2}$ and pays $S_{2}-S_{1}$ to $P_{1}$ (if and only if there is an MFN clause in any settlement between $\mathrm{D}$ and $\mathrm{P}_{1}$ ); if $\mathrm{D}$ rejects $\mathrm{P}_{2}$ 's demand and goes to trial, then $\mathrm{x}_{2}$ is revealed at trial, D pays $x_{2}$ to $P_{2}$ and nothing more to $P_{1}$, and then $P_{2}$ and D pay their respective court costs. If $\mathrm{S}_{2} \leq \mathrm{S}_{1}$, and D accepts $\mathrm{S}_{2}$, then D pays $\mathrm{S}_{2}$ to $\mathrm{P}_{2}$ and nothing more to $\mathrm{P}_{1}$ (even if there was an MFN clause in a previous agreement between $P_{1}$ and D). Finally, the plaintiffs are "time inflexible" in that they cannot adjust the timing of their negotiation with D by either delaying or moving early.

Although each of the bargaining subgames examined in the next two sections differs in some respects, their equilibria have similar attributes. Equilibrium behavior for a plaintiff will involve a settlement demand function that maps the interval of types, $[\underline{x}, \bar{x}]$, into an interval of settlement demands, $[\underline{S}, \bar{S}]$, with higher types making higher demands. Equilibrium behavior for the defendant will involve a probability of rejection function which is continuous on $[\underline{\mathrm{S}}, \overline{\mathrm{S}}]$, begins at zero and is strictly increasing up to (at most) one, whereafter it remains constant at one. ${ }^{6}$ We will rely on these properties to motivate the derivation of the equilibrium strategies.

${ }^{6}$ These properties are direct extensions of those proven in Reinganum and Wilde (1986). Notice that monotonicity of the probability of rejection implies its continuity since, if there were a jump (which would be upward), that type making the demand just above the jump could make an infinitesimal reduction in demand and enjoy a non-infinitesimal decrease in the probability of rejection. However, an upward jump can (and sometimes does) occur for $\mathrm{S}>\overline{\mathrm{S}}$, since there is no type which would thereby be induced to defect. 


\section{Equilibrium Analysis of the Two-Stage Signaling Game When There is No MFN Clause}

Since the levels of expected damages for the plaintiffs, $\mathrm{x}_{1}$ and $\mathrm{x}_{2}$, are independent and identically distributed random variables from the perspective of $\mathrm{D}$ and the other plaintiff, the twostage game is simply the concatenation of two independent, one-stage signaling games as discussed in Reinganum and Wilde (1986). For completeness, we provide the necessary detail of such a onestage game between $\mathrm{P}$ and $\mathrm{D}$, where $\mathrm{P}$ is privately informed about his expected level of damages $\mathrm{x}$ $\in[\underline{\mathrm{x}}, \overline{\mathrm{x}}]$, it is common knowledge that D's prior on these damages is a density $\mathrm{f}(\bullet)$, which is everywhere positive on [ $\underline{\mathrm{x}}, \overline{\mathrm{x}}]$, and court costs are as described in Section 2. We use a subscript '0' to indicate the analysis and solution when there is no MFN, and subscripts ' 1 ' and ' 2 ' in later sections when the analysis involves an MFN, as this requires distinguishing the two subgames.

D observes P's demand $S$ and forms beliefs, $\mathrm{b}_{0}(\mathrm{~S})$, about P's type. Since D wants to

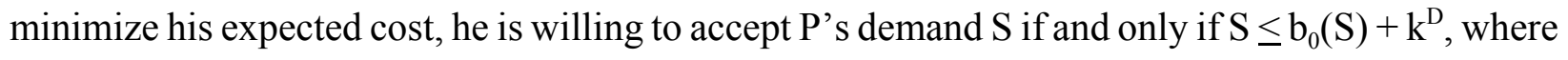
the right-hand-side is what $\mathrm{D}$ anticipates he would pay if there were a trial against $\mathrm{P} .^{7} \quad$ Let $\mathrm{r}_{0}(\mathrm{~S})$ denote D's probability of rejecting a demand of S. Then P's expected payoff from making such a demand, denoted $\pi_{0}^{\mathrm{P}}(\mathrm{S})$, is:

$$
\pi_{0}^{\mathrm{P}}(\mathrm{S})=\left(1-\mathrm{r}_{0}(\mathrm{~S})\right) \mathrm{S}+\mathrm{r}_{0}(\mathrm{~S})\left(\mathrm{x}-\mathrm{k}^{\mathrm{P}}\right)
$$

and $\mathrm{P}$ chooses $\mathrm{S}$ so as to maximize her expected payoff. Let $\mathrm{S}_{0} *(\mathrm{x})$ denote the equilibrium revealing settlement demand made by a $\mathrm{P}$ of type $\mathrm{x}$, and let $\mathrm{r}_{0} *(\mathrm{~S})$ be the equilibrium rejection function for $\mathrm{D}$. Then $\mathrm{S}_{0} *(\mathrm{x})$ and $\mathrm{r}_{0} *(\mathrm{~S})$ should satisfy the following conditions:
a) $\mathrm{S}_{0} *(\mathrm{x})=\mathrm{x}+\mathrm{k}^{\mathrm{D}}$;
b) $1-\mathrm{r}_{0}^{*}(\mathrm{~S})-\left(\mathrm{S}-\mathrm{x}+\mathrm{k}^{\mathrm{P}}\right) \mathrm{r}_{0} *^{\prime}(\mathrm{S})=0$;

7 Thus, D's payoff consists of his expected costs, which are non-negative. 
c) $\mathrm{r}_{0} *\left(\mathrm{~S}_{0} *(\underline{\mathrm{x}})\right)=0$.

Condition (a) provides the revealing demand that a P should make, which makes D indifferent between trial and settlement. In a revealing equilibrium, D's beliefs should be correct: $\mathrm{b}_{0} *\left(\mathrm{~S}_{0} *(\mathrm{x})\right)$ $=\mathrm{x}$, for all $\mathrm{x}$; hence, from the demand made by $\mathrm{P}, \mathrm{D}$ can infer which type of $\mathrm{P}$ would make that demand (that is, $\left.\mathrm{b}_{0}{ }^{*}(\mathrm{~S})=\mathrm{S}-\mathrm{k}^{\mathrm{D}}\right)$. Condition (b) says that $\mathrm{S}_{0}$ * should maximize P's expected payoff, accounting for D's equilibrium rejection function $r_{0} *(S)$, while condition (c) provides the boundary requirement that $\mathrm{D}$ should not reject the lowest rational demand any $\mathrm{P}$ would make (that is, $\underline{\mathrm{x}}+\mathrm{k}^{\mathrm{D}}$, which is the minimum $\mathrm{D}$ would pay were he to go to trial against any type of $\mathrm{P}$ ).

Upon substitution of $\mathrm{x}=\mathrm{S}-\mathrm{k}^{\mathrm{D}}$ from condition (a) into condition (b), we obtain the following differential equation,

$$
1-\mathrm{r}_{0} *(\mathrm{~S})-\mathrm{Kr}_{0}{ }^{\prime}(\mathrm{S})=0,
$$

whose solution, employing condition (c), is straightforward. This leads to the following proposition which summarizes the equilibrium strategies for $\mathrm{D}$ and $\mathrm{P}$, as well as D's equilibrium beliefs, in the one-stage game (see the Appendix for the proof). ${ }^{8}$

Proposition 1. Let $\underline{\mathrm{S}}=\underline{\mathrm{x}}+\mathrm{k}^{\mathrm{D}}$ and $\overline{\mathrm{S}}=\overline{\mathrm{x}}+\mathrm{k}^{\mathrm{D}}$. For the single-stage signaling game between

$\mathrm{P}$ and $\mathrm{D}$, the following strategies $\left(\mathrm{r}_{0} *(\mathrm{~S}), \mathrm{S}_{0} *(\mathrm{x})\right)$ and beliefs $\mathrm{b}_{0} *(\mathrm{~S})$ provide the unique revealing equilibrium.

$$
\text { (i) } \mathrm{r}_{0}^{*}(\mathrm{~S})= \begin{cases}1 & \mathrm{~S}>\overline{\mathrm{S}}, \\ 1-\exp \{-(\mathrm{S}-\underline{\mathrm{S}}) / \mathrm{K}\} & \mathrm{S} \in[\underline{\mathrm{S}}, \overline{\mathrm{S}}], \\ 0 & \mathrm{~S}<\underline{\underline{S}} .\end{cases}
$$

${ }^{8}$ For the technical afficionados, this equilibrium (and the other equilibria discussed in this paper) is the unique Perfect Bayesian equilibrium surviving the D1 refinement of Cho and Kreps (1987). 

(ii) $\mathrm{S}_{0}^{*}(\mathrm{x})=\mathrm{x}+\mathrm{k}^{\mathrm{D}}$,
$\mathrm{x} \in[\underline{\mathrm{x}}, \overline{\mathrm{x}}]$.
(iii) $b_{0}^{*}(\mathrm{~S})=\left\{\begin{array}{l}\overline{\mathrm{x}} \\ \mathrm{S}-\mathrm{k}^{\mathrm{D}} \\ \underline{\mathrm{x}}\end{array}\right.$
$\mathrm{S}>\overline{\mathrm{S}}$
$\mathrm{S} \in[\underline{\mathrm{S}}, \overline{\mathrm{S}}]$
$\mathrm{S}<\underline{\mathrm{S}}$

Thus, in the two-stage game without an MFN, $\mathrm{P}_{1}$ and $\mathrm{D}$ play the single-stage game equilibrium strategies as specified above, and either $\mathrm{D}$ accepts the demand or $\mathrm{D}$ rejects it and $\mathrm{P}_{1}$ and D go to trial; this is followed by $\mathrm{P}_{2}$ and D playing the single-stage game equilibrium strategies as specified above, and either $\mathrm{D}$ accepts the demand or $\mathrm{D}$ rejects it and $\mathrm{P}_{2}$ and $\mathrm{D}$ go to trial. Let $\hat{\pi}_{0}^{\mathrm{P}}\left(\mathrm{x}_{\mathrm{i}}\right)$ denote the equilibrium type-specific (reduced-form) payoff for plaintiff $\mathrm{i}$; for example, $\hat{\pi}_{0}^{\mathrm{P}}\left(\mathrm{x}_{1}\right) \equiv$ $\pi_{0}^{\mathrm{P}}\left(\mathrm{S}_{0} *\left(\mathrm{x}_{1}\right)\right)$ is the reduced-form payoff for $\mathrm{P}_{1}$. Then $\hat{\pi}_{0}^{\mathrm{P}}\left(\mathrm{x}_{\mathrm{i}}\right)=\mathrm{S}_{0} *\left(\mathrm{x}_{\mathrm{i}}\right)-\mathrm{Kr}_{0} *\left(\mathrm{~S}_{0} *\left(\mathrm{x}_{\mathrm{i}}\right)\right), \mathrm{i}=1,2$. Similarly, the defendant's reduced-form payoff is $\hat{\pi}_{0}^{\mathrm{D}}\left(\mathrm{x}_{1}, \mathrm{x}_{2}\right)=\mathrm{S}_{0} *\left(\mathrm{x}_{1}\right)+\mathrm{S}_{0} *\left(\mathrm{x}_{2}\right)=\mathrm{x}_{1}+\mathrm{x}_{2}+2 \mathrm{k}^{\mathrm{D}}$. Note, this is not to imply that $\mathrm{D}$ always settles, but that he pays $\mathrm{x}_{\mathrm{i}}+\mathrm{k}^{\mathrm{D}}$ either in settlement or trial against $P_{\mathrm{i}}$.

\section{Equilibrium Analysis of the Two-Stage Signaling Game When There is an MFN Clause Analyzing the Signaling Game's Second Stage}

Now assume that bargaining proceeds as proposed in Section 2 above with the feature that any settlement between $\mathrm{P}_{1}$ and $\mathrm{D}$ includes an MFN clause for future agreements between $\mathrm{D}$ and other plaintiffs; we return to consider whether $\mathrm{P}_{1}$ and $\mathrm{D}$ would agree to include such a clause later in Section 5. Thus, $\mathrm{P}_{2}$ 's equilibrium demand, $\mathrm{S}_{2}{ }^{*}$ may be influenced by the level of $\mathrm{S}_{1}$ (assuming settlement in stage 1), as may the rejection probability that $\mathrm{D}$ uses when bargaining with $\mathrm{P}_{2}$. Of course, if $\mathrm{P}_{1}$ and $\mathrm{D}$ went to trial, then the bargaining game between $\mathrm{P}_{2}$ and $\mathrm{D}$ is completely characterized by Proposition 1 above. 
Hence, assume that $P_{1}$ and $D$ settled at the amount $S_{1}$ and that $P_{2}$ demands $S_{2}$. Let $b_{2}\left(S_{2} ; S_{1}\right)$ be D's belief about what type of $\mathrm{P}_{2}$ would make such a demand. If $\mathrm{S}_{2} \leq \mathrm{S}_{1}$, then D's (second-stage) cost from accepting the demand $\mathrm{S}_{2}$ is simply $\mathrm{S}_{2}$; if $\mathrm{S}_{2}>\mathrm{S}_{1}$, then D's (second-stage) cost from accepting the demand $\mathrm{S}_{2}$ is $\mathrm{S}_{2}+\mathrm{S}_{2}-\mathrm{S}_{1}$; if D rejects the demand, then since it is a dominant strategy for $\mathrm{P}_{2}$ to proceed to trial, D's anticipated (second-stage) cost is $\mathrm{b}_{2}\left(\mathrm{~S}_{2} ; \mathrm{S}_{1}\right)+\mathrm{k}^{\mathrm{D}}$. Thus, if $\mathrm{S}_{2} \leq \mathrm{S}_{1}$, then $D$ is willing to accept $S_{2}$ if $S_{2} \leq b_{2}\left(S_{2} ; S_{1}\right)+k^{D}$ while if $S_{2}>S_{1}$, then $D$ is willing to accept $S_{2}$ if $S_{2}$ $\leq\left(\mathrm{b}_{2}\left(\mathrm{~S}_{2} ; \mathrm{S}_{1}\right)+\mathrm{k}^{\mathrm{D}}+\mathrm{S}_{1}\right) / 2$.

As in Section 3 above, the second-stage first-mover $\left(\mathrm{P}_{2}\right)$ can choose a demand that makes $\mathrm{D}$ indifferent between his (second-stage) cost under settlement and his anticipated (second-stage) cost from trial, inducing $\mathrm{D}$ to randomize between accepting and rejecting the demand. When $\mathrm{x}_{2}+$ $\mathrm{k}^{\mathrm{D}} \leq \mathrm{S}_{1}$, a revealing equilibrium would involve $\mathrm{P}_{2}$ making the demand $\mathrm{S}_{2}=\mathrm{x}_{2}+\mathrm{k}^{\mathrm{D}}$, while if $\mathrm{x}_{2}+\mathrm{k}^{\mathrm{D}}$ $>\mathrm{S}_{1}$, a revealing equilibrium would involve $\mathrm{P}_{2}$ demanding $\mathrm{S}_{2}=\left(\mathrm{x}_{2}+\mathrm{k}^{\mathrm{D}}+\mathrm{S}_{1}\right) / 2$. In each setting, $\mathrm{D}$ is then forced to a point of indifference between accepting the demand or going to trial.

Let $\mathrm{r}_{2}\left(\mathrm{~S}_{2} ; \mathrm{S}_{1}\right)$ be D's probability of rejecting $\mathrm{P}_{2}$ 's demand, which means that $\mathrm{P}_{2}$ 's expected payoff is:

$$
\pi_{2}^{\mathrm{P}}\left(\mathrm{S}_{2} ; \mathrm{S}_{1}\right)=\left(1-\mathrm{r}_{2}\left(\mathrm{~S}_{2} ; \mathrm{S}_{1}\right)\right) \mathrm{S}_{2}+\mathrm{r}_{2}\left(\mathrm{~S}_{2} ; \mathrm{S}_{1}\right)\left(\mathrm{x}_{2}-\mathrm{k}^{\mathrm{P}}\right) .
$$

Let $\mathrm{S}_{2} *\left(\mathrm{x}_{2} ; \mathrm{S}_{1}\right)$ denote the equilibrium revealing settlement demand made by a $\mathrm{P}_{2}$ of type $\mathrm{x}_{2}$, when $\mathrm{P}_{1}$ had previously settled with $\mathrm{D}$ at $\mathrm{S}_{1}$, and let $\mathrm{r}_{2}{ }^{*}\left(\mathrm{~S}_{2} ; \mathrm{S}_{1}\right)$ be the equilibrium rejection function for $D$, when $\mathrm{P}_{2}$ demands $\mathrm{S}_{2}$ and $\mathrm{P}_{1}$ had previously settled with $\mathrm{D}$ at $\mathrm{S}_{1}$. Then $\mathrm{S}_{2} *\left(\mathrm{x}_{2} ; \mathrm{S}_{1}\right)$ has the two-part form described above and $r_{2} *\left(S_{2} ; S_{1}\right)$ should satisfy the following first order condition for all $\mathrm{S}_{1}$ :

$$
\left.\mathrm{b}^{\prime}\right) 1-\mathrm{r}_{2} *\left(\mathrm{~S}_{2} ; \mathrm{S}_{1}\right)-\left(\mathrm{S}_{2}-\mathrm{x}_{2}+\mathrm{k}^{\mathrm{P}}\right) \mathrm{r}_{2} *^{\prime}\left(\mathrm{S}_{2} ; \mathrm{S}_{1}\right)=0 \text {. }
$$

This condition is parallel to our earlier condition (b). When $\mathrm{x}_{2}+\mathrm{k}^{\mathrm{D}} \leq \mathrm{S}_{1}$ we invert the revealing 
demand for $\mathrm{P}_{2}$ and substitute $\mathrm{x}_{2}=\mathrm{S}_{2}-\mathrm{k}^{\mathrm{D}}$ into $\left(\mathrm{b}^{\prime}\right)$ to obtain the differential equation:

$$
1-\mathrm{r}_{2}{ }^{*}\left(\mathrm{~S}_{2} ; \mathrm{S}_{1}\right)-\mathrm{Kr}_{2}{ }^{\prime}\left(\mathrm{S}_{2} ; \mathrm{S}_{1}\right)=0 \text {, }
$$

which has the same structure as equation (1). Since $\mathrm{S}_{2} \leq \mathrm{S}_{1}$, the appropriate boundary condition is $r_{2} *\left(S_{2} *\left(\underline{x} ; S_{1}\right) ; S_{1}\right)=0$, which is parallel to our earlier condition (c). This means that when $S_{2} \leq S_{1}$, $\mathrm{r}_{2} *\left(\mathrm{~S}_{2} ; \mathrm{S}_{1}\right)=\mathrm{r}_{0} *\left(\mathrm{~S}_{2}\right)$.

On the other hand, if $x_{2}+k^{D}>S_{1}$, then we invert the revealing demand for $P_{2}$ and substitute $\mathrm{x}_{2}=2 \mathrm{~S}_{2}-\mathrm{S}_{1}-\mathrm{k}^{\mathrm{D}}$ into $\left(\mathrm{b}^{\prime}\right)$, yielding the following differential equation, which must again hold for all possible $S_{1}$.

$$
1-\mathrm{r}_{2} *\left(\mathrm{~S}_{2} ; \mathrm{S}_{1}\right)+\left(\mathrm{S}_{2}-\left(\mathrm{S}_{1}+\mathrm{K}\right)\right) \mathrm{r}_{2}{ }^{\prime}\left(\mathrm{S}_{2} ; \mathrm{S}_{1}\right)=0 .
$$

Since $r_{2} *\left(S_{2} ; S_{1}\right)$ is continuous at $S_{2}=S_{1}$ (see the earlier footnote on continuity of the rejection function), the appropriate boundary condition for this equation is that:

$$
\mathrm{r}_{2} *\left(\mathrm{~S}_{1} ; \mathrm{S}_{1}\right)=\mathrm{r}_{0} *\left(\mathrm{~S}_{1}\right)
$$

which again must hold for all $\mathrm{S}_{1}$. As indicated earlier, for revelation we will need $\mathrm{r}_{2}{ }^{*}\left(\mathrm{~S}_{2} ; \mathrm{S}_{1}\right) \geq 0$. If $\mathrm{r}_{2} *\left(\mathrm{~S}_{2} ; \mathrm{S}_{1}\right)$ is less than 1 then from equation (3) we see that $\mathrm{S}_{2} *\left(\mathrm{x}_{2} ; \mathrm{S}_{1}\right)$ must be less than $\mathrm{S}_{1}+\mathrm{K}$. When $\mathrm{P}_{2}$ 's demand is in this range, then all types settle with positive probability. On the other hand, if $\mathrm{S}_{2} *\left(\mathrm{x}_{2} ; \mathrm{S}_{1}\right) \geq \mathrm{S}_{1}+\mathrm{K}$, then (3) can only be solved for a rejection function such that $\mathrm{r}_{2} *\left(\mathrm{~S}_{2} ; \mathrm{S}_{1}\right)=$ 1 and $\mathrm{r}_{2}{ }^{\prime \prime}\left(\mathrm{S}_{2} ; \mathrm{S}_{1}\right)=0$. In this case, demands are being rejected for sure, which means that each type goes to trial and gets their expected damages less $\mathrm{k}^{\mathrm{P}}$.

Thus, there are three parts to the probability of rejection function. When $S_{2} \leq S_{1}$ the MFN constraint is not binding and $r_{2} *\left(S_{2} ; S_{1}\right)=r_{0} *\left(S_{2}\right)$. When $S_{1} \leq S_{2} \leq S_{1}+K$, then $r_{2} *\left(S_{2} ; S_{1}\right)=1-\left\{\left[S_{1}\right.\right.$ $\left.\left.+\mathrm{K}-\mathrm{S}_{2}\right] / \mathrm{K}\right\} \exp \left\{-\left(\mathrm{S}_{1}-\underline{\mathrm{S}}\right) / \mathrm{K}\right\}$. Note that this function is increasing and linear in $\mathrm{S}_{2}$, has a slope equal to the slope of $r_{0} *\left(S_{2}\right)$ at $S_{2}=S_{1}$, and equals 1 if $S_{2}=S_{1}+K$. Finally, if $S_{2}>S_{1}+K$, then 
$\mathrm{r}_{2} *\left(\mathrm{~S}_{2} ; \mathrm{S}_{1}\right)=1$.

Proposition 2 summarizes the above discussion and also provides $\mathrm{P}_{2}$ 's equilibrium demands as well as D's beliefs (the proof is in the Appendix). ${ }^{9}$

Proposition 2. Let $\underline{\mathrm{S}}=\underline{\mathrm{x}}+\mathrm{k}^{\mathrm{D}}$ and $\overline{\mathrm{S}}_{2}\left(\mathrm{~S}_{1}\right)=\left(\overline{\mathrm{x}}+\mathrm{k}^{\mathrm{D}}+\mathrm{S}_{1}\right) / 2$. The following strategies $\left(\mathrm{r}_{2} *\left(\mathrm{~S}_{2} ; \mathrm{S}_{1}\right), \mathrm{S}_{2} *\left(\mathrm{x}_{2} ; \mathrm{S}_{1}\right)\right)$ and beliefs $\mathrm{b}_{2} *\left(\mathrm{~S}_{2} ; \mathrm{S}_{1}\right)$ provide the unique revealing equilibrium for period 2.

$$
\begin{aligned}
& \text { (i) } \mathrm{r}_{2} *\left(\mathrm{~S}_{2} ; \mathrm{S}_{1}\right)= \begin{cases}1 & \mathrm{~S}_{2}>\mathrm{S}_{1}+\mathrm{K} \\
1-\left\{\left[\mathrm{S}_{1}+\mathrm{K}-\mathrm{S}_{2}\right] / \mathrm{K}\right\} \exp \left\{-\left(\mathrm{S}_{1}-\underline{\mathrm{S}}\right) / \mathrm{K}\right\} & \mathrm{S}_{2} \in\left[\mathrm{S}_{1}, \mathrm{~S}_{1}+\mathrm{K}\right] \\
1-\exp \left\{-\left(\mathrm{S}_{2}-\underline{\mathrm{S}}\right) / \mathrm{K}\right\} & \mathrm{S}_{2} \in\left[\underline{\mathrm{S}}, \mathrm{S}_{1}\right] \\
0 & \mathrm{~S}_{2}<\underline{\mathrm{S}} .\end{cases} \\
& \text { (ii) } \mathrm{S}_{2}^{*}\left(\mathrm{x}_{2} ; \mathrm{S}_{1}\right)= \begin{cases}\left(\mathrm{x}_{2}+\mathrm{k}^{\mathrm{D}}+\mathrm{S}_{1}\right) / 2 & \mathrm{x}_{2} \in\left[\mathrm{S}_{1}-\mathrm{k}^{\mathrm{D}}, \overline{\mathrm{x}}\right] \\
\mathrm{x}_{2}+\mathrm{k}^{\mathrm{D}} & \mathrm{x}_{2} \in\left[\underline{\mathrm{x}}, \mathrm{S}_{1}-\mathrm{k}^{\mathrm{D}}\right]\end{cases} \\
& \overline{\mathrm{x}} \quad \mathrm{S}_{2}>\overline{\mathrm{S}}_{2}\left(\mathrm{~S}_{1}\right) \\
& \text { (iii) } \mathrm{b}_{2} *\left(\mathrm{~S}_{2} ; \mathrm{S}_{1}\right)= \begin{cases}2 \mathrm{~S}_{2}-\mathrm{k}^{\mathrm{D}}-\mathrm{S}_{1} & \mathrm{~S}_{2} \in\left[\mathrm{S}_{1}, \overline{\mathrm{S}}_{2}\left(\mathrm{~S}_{1}\right)\right. \\
\mathrm{S}_{2}-\mathrm{k}^{\mathrm{D}} & \mathrm{S}_{2} \in\left[\underline{\mathrm{S}}, \mathrm{S}_{1}\right]\end{cases} \\
& \underline{\mathrm{X}} \quad \mathrm{S}_{2}<\underline{\mathrm{S}} \text {. }
\end{aligned}
$$

Note that if $\bar{S}_{2}\left(S_{1}\right) \geq S_{1}+K$, then types making demands $S_{2} \geq S_{1}+K$ reveal, but these demands are rejected with probability 1 . As is discussed in the proof (see the Appendix), these types would have to cut their demands below what they could get at trial in order to settle with positive probability, which is irrational. If, on the other hand, $\overline{\mathrm{S}}_{2}\left(\mathrm{~S}_{1}\right)<\mathrm{S}_{1}+\mathrm{K}$, then even $\overline{\mathrm{x}}$ 's revealing demand is less than $\mathrm{S}_{1}+\mathrm{K}$, so that all types have a positive probability of settling.

These two circumstances are illustrated in Figure 1 below, with the left-hand-panel

9 The Proposition claims uniqueness. As discussed in the Appendix, there is a trivial multiplicity of revealing equilibrium demands that are rejected with probability one; the ones we emphasize are the lowest such revealing demands, and are the natural extension of the demands that enjoy a positive probability of acceptance. 
illustrating $r_{2} *\left(S_{2} ; S_{1}\right)$ when $\bar{S}_{2}\left(S_{1}\right)<S_{1}+K$ and the right-hand-panel illustrating $r_{2} *\left(S_{2} ; S_{1}\right)$ when
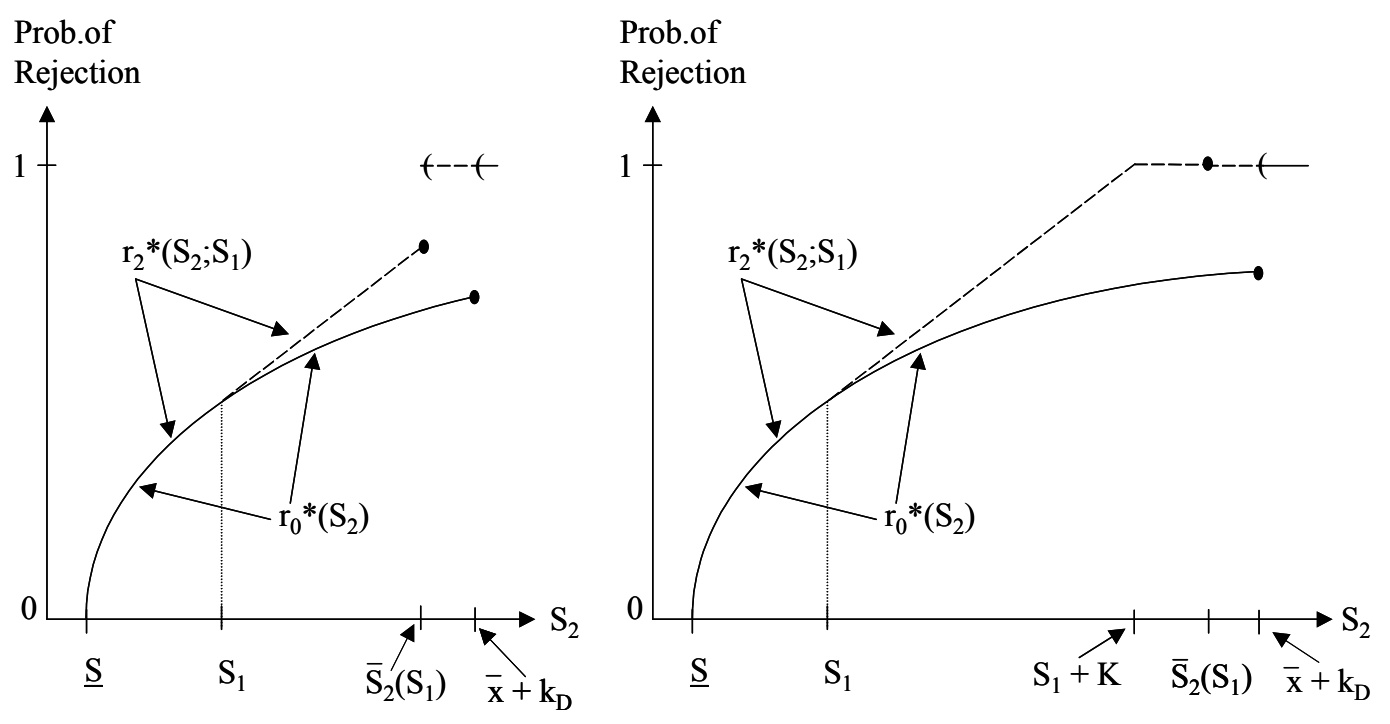

Figure 1: Equilibrium Probability of Rejection

$\bar{S}_{2}\left(S_{1}\right)>S_{1}+K$. Note that both panels also illustrate the rejection function D would employ if there were no $\mathrm{MFN}$ in use (i.e., $\left.\mathrm{r}_{0} *\left(\mathrm{~S}_{2}\right)\right)$.

Figure 2 below illustrates the revealing equilibrium demand function for $\mathrm{P}_{2}$. There is a kink at $\mathrm{S}_{1}$; higher demands are the simple average of the non-MFN-constrained demand $\left(\mathrm{x}_{2}+\mathrm{k}^{\mathrm{D}}\right)$ and the demand made by $P_{1}$. This is how $P_{1}$ 's demand constrains $P_{2}{ }^{\prime}$ s demand if $x_{2}+k^{D}>S_{1}$. As will be demonstrated below, when we discuss the equilibrium for the first stage, the MFN will bind whenever $\mathrm{x}_{1}<\mathrm{x}_{2}$. Note that, if there were no MFN, then there would be no kink at $\mathrm{S}_{1}$ and demands would follow $\mathrm{x}_{2}+\mathrm{k}^{\mathrm{D}}$.

Analyzing the Signaling Game's First Stage

First, let us consider D's expected continuation value; that is, given any outcome in stage 1, what $\mathrm{D}$ expects his stage-two cost will be. We will show that the expected continuation value for 


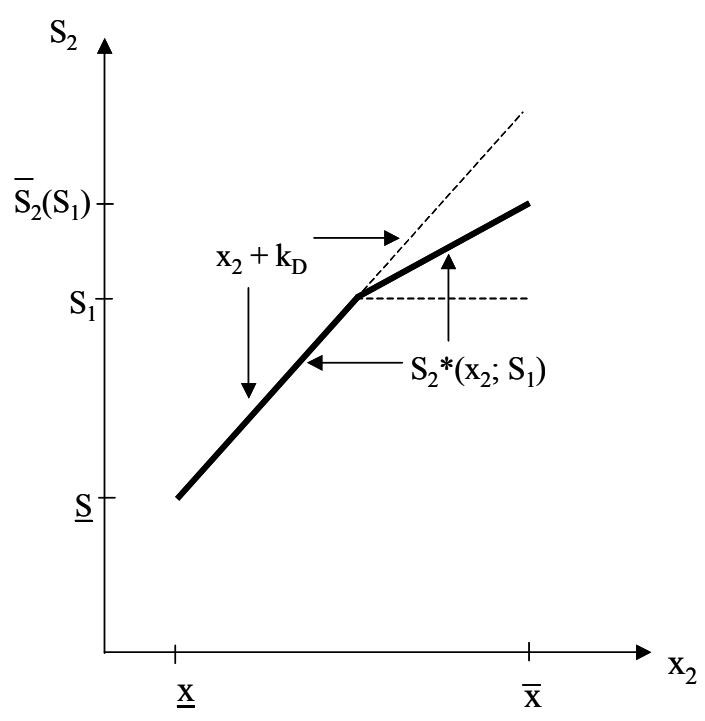

Figure 2: Equilibrium Settlement Demands

$\mathrm{D}$ is simply $\mathrm{E}\left(\mathrm{x}_{2}\right)+\mathrm{k}^{\mathrm{D}}$; that is, $\mathrm{P}_{2}$ 's expected damages plus D's court costs. To see this, consider the alternative ranges for $\mathrm{P}_{2}$ 's demands. If $\mathrm{S}_{2} *\left(\mathrm{x}_{2} ; \mathrm{S}_{1}\right) \in\left[\underline{\mathrm{S}}, \mathrm{S}_{1}\right]$ then D's continuation value if $\mathrm{P}_{2}$ 's type is $\mathrm{x}_{2}$, denoted ${ }^{10}$ as $\mathrm{CV}^{\mathrm{D}}\left(\mathrm{x}_{2}\right)$, is $\left(1-\mathrm{r}_{2} *\left(\mathrm{~S}_{2} *\left(\mathrm{x}_{2} ; \mathrm{S}_{1}\right) ; \mathrm{S}_{1}\right)\right) \mathrm{S}_{2} *\left(\mathrm{x}_{2} ; \mathrm{S}_{1}\right)+\mathrm{r}_{2} *\left(\mathrm{~S}_{2} *\left(\mathrm{x}_{2} ; \mathrm{S}_{1}\right) ; \mathrm{S}_{1}\right)\left(\mathrm{x}_{2}+\mathrm{k}^{\mathrm{D}}\right)$. Since $\mathrm{P}_{2}$ 's demand in this region is $\mathrm{x}_{2}+\mathrm{k}^{\mathrm{D}}$, then for these types, $\mathrm{CV}^{\mathrm{D}}\left(\mathrm{x}_{2}\right)=\mathrm{x}_{2}+\mathrm{k}^{\mathrm{D}}$; in other words, $D$ is indifferent between settlement and trial for each such type. If $\mathrm{S}_{2} *\left(\mathrm{x}_{2} ; \mathrm{S}_{1}\right) \in\left[\mathrm{S}_{1}, \mathrm{~S}_{1}+\mathrm{K}\right]$, then D's continuation value if $\mathrm{P}_{2}$ 's type is $\mathrm{x}_{2}$ is $\mathrm{CV}^{\mathrm{D}}\left(\mathrm{x}_{2}\right)=\left(1-\mathrm{r}_{2}{ }^{*}\left(\mathrm{~S}_{2} *\left(\mathrm{x}_{2} ; \mathrm{S}_{1}\right) ; \mathrm{S}_{1}\right)\right)\left(2 \mathrm{~S}_{2} *\left(\mathrm{x}_{2} ; \mathrm{S}_{1}\right)-\mathrm{S}_{1}\right)+$ $\mathrm{r}_{2} *\left(\mathrm{~S}_{2} *\left(\mathrm{x}_{2} ; \mathrm{S}_{1}\right) ; \mathrm{S}_{1}\right)\left(\mathrm{x}_{2}+\mathrm{k}^{\mathrm{D}}\right)=\mathrm{x}_{2}+\mathrm{k}^{\mathrm{D}}$, since $\mathrm{S}_{2} *\left(\mathrm{x}_{2} ; \mathrm{S}_{1}\right)=\left(\mathrm{x}_{2}+\mathrm{k}^{\mathrm{D}}+\mathrm{S}_{1}\right) / 2$. Thus, once again, $\mathrm{CV}^{\mathrm{D}}\left(\mathrm{x}_{2}\right)$ $=\mathrm{x}_{2}+\mathrm{k}^{\mathrm{D}}$, and $\mathrm{D}$ is indifferent between trial and settlement. Finally, when $\mathrm{S}_{2} *\left(\mathrm{x}_{2} ; \mathrm{S}_{1}\right)>\mathrm{S}_{1}+\mathrm{K}, \mathrm{D}$ always rejects and goes to trial, so that $\mathrm{CV}^{\mathrm{D}}\left(\mathrm{x}_{2}\right)=\mathrm{x}_{2}+\mathrm{k}^{\mathrm{D}}$ again. Therefore, D's expected continuation value, $\mathrm{ECV}^{\mathrm{D}}$, is $\mathrm{E}\left(\mathrm{x}_{2}\right)+\mathrm{k}^{\mathrm{D}}$. Note that this is the same expected continuation value for

${ }^{10}$ Note that, while in principle D's continuation value might be influenced by $S_{1}$, we will see that the continuation value is independent of $\mathrm{S}_{1}$, and thus we use the notation $\mathrm{CV}^{\mathrm{D}}\left(\mathrm{x}_{2}\right)$. 
$\mathrm{D}$ as if there were no MFN in use, since the second stage in Section 3 also results in D being indifferent between trial and settlement. In other words, D is "fully extracted" with or without an MFN in any agreement reached in the first stage (or, should D go to trial in the first stage). This means that $\mathrm{D}$ is willing to accept $\mathrm{P}_{1}$ 's demand of $\mathrm{S}_{1}$ if and only if $\mathrm{S}_{1}+\mathrm{ECV}^{\mathrm{D}} \leq \mathrm{b}_{1}\left(\mathrm{~S}_{1}\right)+\mathrm{k}^{\mathrm{D}}+\mathrm{ECV}^{\mathrm{D}}$, that is, if and only if $S_{1} \leq b_{1}\left(S_{1}\right)+k^{D}$, where $b_{1}\left(S_{1}\right)$ is D's belief about what type of $P_{1}$ would make such a demand.

Let $r_{1}\left(S_{1}\right)$ be D's probability of rejecting $P_{1}$ 's demand of $S_{1}$. Thus, $P_{1}$ 's expected payoff from such a demand, denoted $\pi_{1}^{\mathrm{P}}\left(\mathrm{S}_{1}\right)$, is as follows:

$$
\pi_{1}^{\mathrm{P}}\left(\mathrm{S}_{1}\right)=\mathrm{r}_{1}\left(\mathrm{~S}_{1}\right)\left(\mathrm{x}_{1}-\mathrm{k}^{\mathrm{P}}\right)+\left(1-\mathrm{r}_{1}\left(\mathrm{~S}_{1}\right)\right)\left(\mathrm{S}_{1}+\mathrm{g}\left(\mathrm{S}_{1}\right)\right)
$$

where $g\left(S_{1}\right)$ is the expected payment by $D$ to $P_{1}$ under an MFN if $D$ settles with $P_{2}$ at an amount $S_{2}$ $\geq \mathrm{S}_{1}$. The first term above on the right reflects the possibility that $\mathrm{D}$ and $\mathrm{P}_{1}$ go to trial while the second term on the right reflects the possibility that $\mathrm{D}$ and $\mathrm{P}_{1}$ settle, and that the settlement uses an MFN.

In the revealing equilibrium for stage two described above, settlements by D which trigger an MFN payment to $\mathrm{P}_{1}$ are made by types $\mathrm{x}_{2}$ in the set $\mathrm{T}\left(\mathrm{S}_{1}\right) \equiv\left[\mathrm{S}_{1}-\mathrm{k}^{\mathrm{D}}, \min \left\{\overline{\mathrm{x}}, \mathrm{S}_{1}+\mathrm{K}+\mathrm{k}^{\mathrm{P}}\right\}\right]$. The left-hand-end of this interval is straightforward to understand: when $\mathrm{S}_{2} *\left(\mathrm{x}_{2} ; \mathrm{S}_{1}\right)=\mathrm{S}_{1}$, then the type making the demand $\mathrm{S}_{2}{ }^{*}\left(\mathrm{x}_{2} ; \mathrm{S}_{1}\right)=\mathrm{x}_{2}+\mathrm{k}^{\mathrm{D}}$ is (simply) the type $\mathrm{x}_{2}=\mathrm{S}_{1}-\mathrm{k}^{\mathrm{D}}$. If $\overline{\mathrm{x}}>\mathrm{S}_{1}+\mathrm{K}+\mathrm{k}^{\mathrm{P}}$, then $\overline{\mathrm{x}}$ - $\mathrm{k}^{\mathrm{P}}>\mathrm{S}_{1}+\mathrm{K}$, so that there is a type $\tilde{\mathrm{x}}_{2}\left(\mathrm{~S}_{1}\right)<\overline{\mathrm{x}}$ such that $\tilde{\mathrm{x}}_{2}\left(\mathrm{~S}_{1}\right)-\mathrm{k}^{\mathrm{P}}=\mathrm{S}_{1}+\mathrm{K}$. This type is making a revealing demand that is just sufficiently large to make D reject it with probability one and for this type $\left(\widetilde{\mathrm{x}}_{2}\left(\mathrm{~S}_{1}\right)\right)$ to be, herself, indifferent between settling and going to trial. This means that $\left(\widetilde{\mathrm{x}}_{2}\left(\mathrm{~S}_{1}\right)\right.$ $\left.+\mathrm{k}^{\mathrm{D}}+\mathrm{S}_{1}\right) / 2=\tilde{\mathrm{x}}_{2}\left(\mathrm{~S}_{1}\right)-\mathrm{k}^{\mathrm{P}}$, or alternatively, $\mathrm{S}_{2}{ }^{*}\left(\tilde{\mathrm{x}}_{2}\left(\mathrm{~S}_{1}\right) ; \mathrm{S}_{1}\right)=\mathrm{S}_{1}+\mathrm{K}$. Thus, if $\overline{\mathrm{x}}>\mathrm{S}_{1}+\mathrm{K}+\mathrm{k}^{\mathrm{P}}$, then the MFN is triggered if $\mathrm{D}$ settles with types in the interval $\left[\mathrm{S}_{1}-\mathrm{k}^{\mathrm{D}}, \mathrm{S}_{1}+\mathrm{K}+\mathrm{k}^{\mathrm{P}}\right)$; D goes to trial with 
probability one (thereby not triggering the MFN) against types in the interval $\left[\mathrm{S}_{1}+\mathrm{K}+\mathrm{k}^{\mathrm{P}}, \overline{\mathrm{x}}\right]$. On the other hand, if $\overline{\mathrm{x}}<\mathrm{S}_{1}+\mathrm{K}+\mathrm{k}^{\mathrm{P}}$, then $\mathrm{D}$ makes an MFN payment to $\mathrm{P}_{1}$ if $\mathrm{D}$ settles with types in the interval $\left[S_{1}-k^{D}, \bar{x}\right]$. Thus, $T\left(S_{1}\right)$ provides the set of types of $P_{2}$ who will make demands that (if $D$ accepts) will generate an MFN-based payment to $\mathrm{P}_{1}$.

This payment is denoted above as $\mathrm{g}\left(\mathrm{S}_{1}\right)$ :

$$
\mathrm{g}\left(\mathrm{S}_{1}\right) \equiv \int_{\mathrm{T}\left(\mathrm{S}_{1}\right)}\left[\left(\mathrm{x}_{2}+\mathrm{k}^{\mathrm{D}}-\mathrm{S}_{1}\right) / 2\right]\left[1-\mathrm{r}_{2} *\left(\left(\mathrm{x}_{2}+\mathrm{k}^{\mathrm{D}}+\mathrm{S}_{1}\right) / 2 ; \mathrm{S}_{1}\right)\right] \mathrm{f}\left(\mathrm{x}_{2}\right) \mathrm{dx} \mathrm{x}_{2}
$$

The term in the first pair of square brackets is simply the excess of the equilibrium demand over $\mathrm{S}_{1}$, $\mathrm{S}_{2} *\left(\mathrm{x}_{2} ; \mathrm{S}_{1}\right)-\mathrm{S}_{1}$, for type $\mathrm{x}_{2}$, while the term in the second pair of square brackets is the equilibrium probability that $\mathrm{D}$ will accept the demand $\mathrm{S}_{2}{ }^{*}\left(\mathrm{x}_{2} ; \mathrm{S}_{1}\right)$. As is shown in the Appendix: 1$) \mathrm{g}\left(\mathrm{S}_{1}\right)>0$ for all $\mathrm{S}_{1} \in[\underline{\mathrm{S}}, \overline{\mathrm{S}})$, and $\left.\mathrm{g}(\overline{\mathrm{S}})=0 ; 2\right) 1+\mathrm{g}^{\prime}\left(\mathrm{S}_{1}\right)>0$ for all $\mathrm{S}_{1} \in[\underline{\mathrm{S}}, \overline{\mathrm{S}}]$; and 3$) \mathrm{g}^{\prime}\left(\mathrm{S}_{1}\right)<+\infty$ for all $\mathrm{S}_{1} \in$ $[\underline{\mathrm{S}}, \overline{\mathrm{S}}]$.

We use these properties below. In particular, $1+\mathrm{g}^{\prime}\left(\mathrm{S}_{1}\right)>0$ means that $\mathrm{P}_{1}$ 's payoff from settling $\left(\mathrm{S}_{1}+\mathrm{g}\left(\mathrm{S}_{1}\right)\right)$ is increasing in $\mathrm{S}_{1}$, providing the usual incentives for (essentially) all types of $\mathrm{P}_{1}$ to be tempted to inflate their demands, making it necessary for D's probability of rejection function to be increasing in $\mathrm{S}_{1}$. The conditions for a revealing equilibrium are analogous to those in Section 3:

e) $\mathrm{S}_{1} *\left(\mathrm{x}_{1}\right)=\mathrm{x}_{1}+\mathrm{k}^{\mathrm{D}}$

f) $\left[1-\mathrm{r}_{1} *\left(\mathrm{~S}_{1}\right)-\left(\mathrm{S}_{1}-\mathrm{X}_{1}+\mathrm{k}^{\mathrm{P}}\right) \mathrm{r}_{1}{ }^{\prime}\left(\mathrm{S}_{1}\right)\right]+\left[\left(1-\mathrm{r}_{1} *\left(\mathrm{~S}_{1}\right)\right) \mathrm{g}^{\prime}\left(\mathrm{S}_{1}\right)-\mathrm{r}_{1}^{* \prime}\left(\mathrm{S}_{1}\right) \mathrm{g}\left(\mathrm{S}_{1}\right)\right]=0$;

g) $\mathrm{r}_{1} *(\underline{\mathrm{S}})=0$.

Condition (e) reflects that, in a revealing equilibrium, D is indifferent between trial and settlement (and thus randomizes with probability $\left.\mathrm{r}_{1}{ }^{*}\right)$, and therefore the revealing equilibrium demand, $\mathrm{S}_{1} *\left(\mathrm{x}_{1}\right)$, is $\mathrm{x}_{1}+\mathrm{k}^{\mathrm{D}}$. Condition $(\mathrm{g})$ provides the boundary requirement that $\mathrm{D}$ accepts the lowest possible 
revealing demand.

We can re-write condition (f) above by collecting terms and substituting $\mathrm{x}_{1}=\mathrm{S}_{1}-\mathrm{k}^{\mathrm{D}}$ (that is, by requiring that the solution be revealing):

$$
\left(1-r_{1}^{*}\left(S_{1}\right)\right)\left(1+g^{\prime}\left(S_{1}\right)\right)-r_{1} *^{\prime}\left(S_{1}\right)\left(K+g\left(S_{1}\right)\right)=0 .
$$

If $0 \leq \mathrm{r}_{1} *\left(\mathrm{~S}_{1}\right)<1$ for all $\mathrm{S}_{1} \in[\underline{\mathrm{S}}, \overline{\mathrm{S}}]$, then the previously asserted properties of $\mathrm{g}\left(\mathrm{S}_{1}\right)$ and $\mathrm{g}^{\prime}\left(\mathrm{S}_{1}\right)$ imply that $\mathrm{r}_{1}{ }^{\prime}\left(\mathrm{S}_{1}\right)>0$ for all $\mathrm{S}_{1} \in[\underline{\mathrm{S}}, \overline{\mathrm{S}}]$. Solving (4) yields the following probability of rejection function for $\mathrm{D}$ (we delay considering specific forms of $\mathrm{g}\left(\mathrm{S}_{1}\right)$ and their effect on $\mathrm{r}_{1} *\left(\mathrm{~S}_{1}\right)$ until the next section):

$$
\mathrm{r}_{1} *\left(\mathrm{~S}_{1}\right)=1-\exp \left\{-\int_{\left[\underline{\mathrm{S}}, \mathrm{S}_{1}\right]}\left(1+\mathrm{g}^{\prime}(\mathrm{t})\right) /(\mathrm{K}+\mathrm{g}(\mathrm{t})) \mathrm{dt}\right\} .
$$

The boundedness of $\mathrm{g}^{\prime}(\mathrm{t})$ guarantees that $0 \leq \mathrm{r}_{1} *\left(\mathrm{~S}_{1}\right)<1$, as assumed above; in the Appendix, we show that this probability of rejection function is a best response for $\mathrm{D}$ to $\mathrm{P}_{1}$ 's revealing equilibrium demand. Our equilibrium is summarized in Proposition 3 below (recall that $\bar{S}$ and $\underline{\mathrm{S}}$ were defined in Proposition 1).

Proposition 3. For the first-stage signaling game between $\mathrm{P}_{1}$ and $\mathrm{D}$, the following strategies $\left(\mathrm{r}_{1} *\left(\mathrm{~S}_{1}\right), \mathrm{S}_{1} *(\mathrm{x})\right)$ and beliefs $\mathrm{b}_{1} *\left(\mathrm{~S}_{1}\right)$ provide the unique revealing equilibrium when an MFN is employed.
(i) $\mathrm{r}_{1} *\left(\mathrm{~S}_{1}\right)=\left\{\begin{array}{l}1 \\ 1-\exp \\ 0\end{array}\right.$
(ii) $\mathrm{S}_{1}^{*}\left(\mathrm{x}_{1}\right)=\mathrm{x}_{1}+\mathrm{k}^{\mathrm{D}}$, $\mathrm{S}_{1}>\overline{\mathrm{S}}$ $\mathrm{S}_{1} \in[\underline{\mathrm{S}}, \overline{\mathrm{S}}]$,
$\mathrm{S}_{1}<\underline{\mathrm{S}}$.
(iii) $b_{1} *\left(S_{1}\right)=\left\{\begin{array}{l}\bar{x} \\ S-k^{D} \\ \underline{x}\end{array}\right.$
$\mathrm{S}_{1}>\overline{\mathrm{S}}$ $\mathrm{S}_{1} \in[\underline{\mathrm{S}}, \overline{\mathrm{S}}]$,
$\mathrm{S}_{1}<\underline{\mathrm{S}}$. $\mathrm{x}_{1} \in[\underline{\mathrm{x}}, \overline{\mathrm{x}}]$. 


\section{Payoffs and Welfare Considerations}

Again, let a “^” on a function be the reduced-form (i.e., equilibrium type-specific) version of the strategies and payoffs specified earlier. ${ }^{11}$ Thus, for example, $\hat{\mathrm{r}}_{0}\left(\mathrm{x}_{1}\right) \equiv \mathrm{r}_{0} *\left(\mathrm{~S}_{0} *\left(\mathrm{x}_{1}\right)\right), \hat{\mathrm{r}}_{1}\left(\mathrm{x}_{1}\right) \equiv$ $\mathrm{r}_{1}{ }^{*}\left(\mathrm{~S}_{1}{ }^{*}\left(\mathrm{x}_{1}\right)\right)$, and $\hat{\mathrm{g}}\left(\mathrm{x}_{1}\right) \equiv \mathrm{g}\left(\mathrm{S}_{1} *\left(\mathrm{x}_{1}\right)\right)$. The expression $\hat{\pi}_{1}^{\mathrm{P}}\left(\mathrm{x}_{1}\right)$ is $\mathrm{P}_{1}$ 's reduced-form expected payoff under an MFN and $\hat{\pi}_{0}^{\mathrm{P}}\left(\mathrm{x}_{1}\right)$ is $\mathrm{P}_{1}$ 's reduced-form payoff with no MFN:

$$
\hat{\pi}_{1}^{\mathrm{P}}\left(\mathrm{x}_{1}\right)=\left(1-\hat{\mathrm{r}}_{1}\left(\mathrm{x}_{1}\right)\right)\left(\mathrm{S}_{1} *\left(\mathrm{x}_{1}\right)+\hat{\mathrm{g}}\left(\mathrm{x}_{1}\right)\right)+\hat{\mathrm{r}}_{1}\left(\mathrm{x}_{1}\right)\left(\mathrm{x}_{1}-\mathrm{k}^{\mathrm{P}}\right),
$$

while

$$
\hat{\pi}_{0}^{\mathrm{P}}\left(\mathrm{x}_{1}\right)=\left(1-\hat{\mathrm{r}}_{0}\left(\mathrm{x}_{1}\right)\right) \mathrm{S}_{0} *\left(\mathrm{x}_{1}\right)+\hat{\mathrm{r}}_{0}\left(\mathrm{x}_{1}\right)\left(\mathrm{x}_{1}-\mathrm{k}^{\mathrm{P}}\right)
$$

Since $\mathrm{S}_{0} *\left(\mathrm{x}_{1}\right)=\mathrm{S}_{1} *\left(\mathrm{x}_{1}\right)=\mathrm{x}_{1}+\mathrm{k}^{\mathrm{D}}$, then a $\mathrm{P}_{1}$ of type $\mathrm{x}_{1}$ prefers to include an MFN clause in the settlement (about which inclusion D is indifferent) if and only if:

$$
\hat{\mathrm{g}}\left(\mathrm{x}_{1}\right) \geq \mathrm{K}\left(\hat{\mathrm{r}}_{1}\left(\mathrm{x}_{1}\right)-\hat{\mathrm{r}}_{0}\left(\mathrm{x}_{1}\right)\right) /\left(1-\hat{\mathrm{r}}_{1}\left(\mathrm{x}_{1}\right)\right) \text {. }
$$

A sufficient condition that guarantees this is true for all types of $\mathrm{P}_{1}$ is that:

$$
\hat{\mathrm{r}}_{1}\left(\mathrm{x}_{1}\right)<\hat{\mathrm{r}}_{0}\left(\mathrm{x}_{1}\right) \text { for all } \mathrm{x}_{1} \in(\underline{\mathrm{x}}, \overline{\mathrm{x}}]
$$

with equality necessary at $\mathrm{x}_{1}=\underline{\mathrm{x}}$ (since under both rejection functions, a demand of $\underline{\mathrm{x}}+\mathrm{k}^{\mathrm{D}}$ is accepted with certainty). Thus all distributions $f(\bullet)$ such that inequality $(6)$ holds guarantee that inequality (5) holds and therefore guarantee that all types of $\mathrm{P}_{1}$ will employ an MFN in the settlement demand, thereby inducing the equilibrium specified by Proposition 2 in Section 4 above. $^{12}$

Note that if inequality (6) holds, it is immediate that $\mathrm{P}_{1}$ 's payoff is higher for two reasons. First, $\mathrm{g}\left(\mathrm{S}_{1}\right)$ is non-negative, so this adds to $\mathrm{P}_{1}$ 's payoff. Second, $\mathrm{P}_{1}$ makes the same demands with

11 Some of the results below hold off the equilibrium path as well as on it, but for ease of exposition, the main text focuses on the equilibrium path.

12 Of course, if inequality (5) does not hold for some $\mathrm{x}_{1}$, that type of $\mathrm{P}_{1}$ would not use an MFN; again, D would be indifferent to its employment. 
or without an MFN, and D is more likely to accept these demands with an MFN: the anticipated rebate means that lower types of $\mathrm{P}_{1}$ are less tempted to mimic higher types and risk trial, so D does not need to reject them at as high a rate (as would be required in the non-MFN case) in order to maintain revelation.

While a full characterization of when $\hat{r}_{1}\left(x_{1}\right)<\hat{r}_{0}\left(x_{1}\right)$ for all $x_{1} \in(\underline{x}, \bar{x}]$ is not possible, the following proposition provides a sufficient condition on $\mathrm{F}(\bullet)$ for this to hold (see the Appendix).

Proposition 4. If $\mathrm{F}(\bullet)$ is the uniform distribution (i.e., $\mathrm{f}(\mathrm{x})=1 /(\overline{\mathrm{x}}-\underline{\mathrm{x}}))$, then $\hat{\mathrm{r}}_{1}\left(\mathrm{x}_{1}\right)$ is always below $\hat{\mathrm{r}}_{0}\left(\mathrm{x}_{1}\right)$ for each type of $\mathrm{P}_{1}$ in $(\underline{\mathrm{x}}, \overline{\mathrm{x}}]$.

Thus, for distributions sufficiently close to the uniform (but possibly with $\mathrm{f}^{\prime}(\bullet)$ either positive or negative, or both), $\mathrm{P}_{1}$ always prefers an MFN.

On the other hand, $\mathrm{P}_{2}$ is never helped (and is sometimes harmed) by the presence of an MFN in the settlement between $\mathrm{P}_{1}$ and $\mathrm{D}$, independent of the distribution of damages. To see this, observe that when $\mathrm{S}_{2} *\left(\mathrm{x}_{2} ; \mathrm{S}_{1} *\left(\mathrm{x}_{1}\right)\right) \in\left[\underline{\mathrm{S}}, \mathrm{S}_{1} *\left(\mathrm{x}_{1}\right)\right]$, then $\mathrm{P}_{2}$ 's equilibrium type-specific payoff under an MFN, $\hat{\pi}_{2}^{\mathrm{P}}\left(\mathrm{x}_{2} ; \mathrm{x}_{1}\right)$ is precisely the same as the equilibrium type-specific payoff without an MFN, $\hat{\pi}_{0}^{\mathrm{P}}\left(\mathrm{x}_{2}\right)$, as both $\mathrm{S}_{2} *\left(\mathrm{x}_{2} ; \mathrm{S}_{1} *\left(\mathrm{x}_{1}\right)\right)$ and $\hat{\mathrm{r}}_{2}\left(\mathrm{x}_{2} ; \mathrm{x}_{1}\right) \equiv \mathrm{r}_{2} *\left(\mathrm{x}_{2}+\mathrm{k}^{\mathrm{D}} ; \mathrm{x}_{1}+\mathrm{k}^{\mathrm{D}}\right)$ are the same over this interval as $\mathrm{S}_{0} *\left(\mathrm{x}_{2}\right)$ and $\hat{\mathrm{r}}_{0}\left(\mathrm{x}_{2}\right)$, respectively. Note also that $\mathrm{S}_{2} *\left(\mathrm{x}_{2} ; \mathrm{S}_{1} *\left(\mathrm{x}_{1}\right)\right) \in\left[\underline{\mathrm{S}}, \mathrm{S}_{1} *\left(\mathrm{x}_{1}\right)\right]$ if and only if $\mathrm{x}_{2} \in\left[\underline{\mathrm{x}}, \mathrm{x}_{1}\right]$.

However, when $\mathrm{S}_{2} *\left(\mathrm{x}_{2} ; \mathrm{S}_{1}\right) \geq \mathrm{S}_{1}^{*}\left(\mathrm{x}_{1}\right)$, then if $\overline{\mathrm{x}}=\min \left\{\overline{\mathrm{x}}, \mathrm{S}_{1} *\left(\mathrm{x}_{1}\right)+\mathrm{K}+\mathrm{k}^{\mathrm{P}}\right\}=$ $\min \left\{\overline{\mathrm{x}}, \mathrm{x}_{1}+2 \mathrm{~K}\right\}$, meaning that $\overline{\mathrm{x}} \leq \mathrm{x}_{1}+2 \mathrm{~K}$, then rejection always occurs with probability less than 1 (except at $\left.\overline{\mathrm{x}}=\mathrm{x}_{1}+2 \mathrm{~K}\right)$ so that:

$$
\hat{\pi}_{2}^{\mathrm{P}}\left(\mathrm{x}_{2} ; \mathrm{x}_{1}\right)=\left(1-\hat{\mathrm{r}}_{2}\left(\mathrm{x}_{2} ; \mathrm{x}_{1}\right)\right) \mathrm{S}_{2} *\left(\mathrm{x}_{2} ; \mathrm{S}_{1} *\left(\mathrm{x}_{1}\right)\right)+\hat{\mathrm{r}}_{2}\left(\mathrm{x}_{2} ; \mathrm{x}_{1}\right)\left(\mathrm{x}_{2}-\mathrm{k}^{\mathrm{P}}\right) \text {, for all } \mathrm{x}_{2} \in\left[\mathrm{x}_{1}, \overline{\mathrm{x}}\right] \text {. }
$$

On the other hand, let $\mathrm{S}_{2} *\left(\mathrm{x}_{2} ; \mathrm{S}_{1}\right) \geq \mathrm{S}_{1} *\left(\mathrm{x}_{1}\right)$ and assume that $\overline{\mathrm{x}}>\mathrm{x}_{1}+2 \mathrm{~K}$. Then, when $\mathrm{x}_{1} \leq \mathrm{x}_{2}<$ $\tilde{\mathrm{x}}_{2}\left(\mathrm{~S}_{1} *\left(\mathrm{x}_{1}\right)\right)=\mathrm{x}_{1}+2 \mathrm{~K}$, the formula for $\hat{\pi}_{2}^{\mathrm{P}}\left(\mathrm{x}_{2} ; \mathrm{x}_{1}\right)$ given above still holds, while when $\mathrm{x}_{1}+2 \mathrm{~K} \leq \mathrm{x}_{2} \leq$ 
$\overline{\mathrm{x}}, \mathrm{P}_{2}$ and $\mathrm{D}$ go to trial with probability one and therefore $\hat{\pi}_{2}^{\mathrm{P}}\left(\mathrm{x}_{2} ; \mathrm{x}_{1}\right)=\mathrm{x}_{2}-\mathrm{k}^{\mathrm{P}}$. In this latter case it is straightforward to see that $\hat{\pi}_{2}^{\mathrm{P}}\left(\mathrm{x}_{2} ; \mathrm{x}_{1}\right)<\hat{\pi}_{0}^{\mathrm{P} *}\left(\mathrm{x}_{2}\right)$, as without the MFN $\mathrm{P}_{2}{ }^{\prime} \mathrm{s}$ demand $\left(\mathrm{x}_{2}+\mathrm{k}^{\mathrm{D}}\right)$ is sometimes accepted by D. That this is also true in the "middle portion," where $\mathrm{x}_{1} \leq \mathrm{x}_{2} \leq \min \{\overline{\mathrm{x}}$, $\left.\mathrm{x}_{1}+2 \mathrm{~K}\right\}$, is less obvious, but is shown in the Appendix. These results are summarized in the following proposition.

Proposition 5. $\mathrm{P}_{2}$ 's type-specific equilibrium payoff, $\hat{\pi}_{2}^{\mathrm{P}}\left(\mathrm{x}_{2} ; \mathrm{x}_{1}\right)$ :

i) $\quad=\hat{\pi}_{0}^{\mathrm{P}}\left(\mathrm{x}_{2}\right)$ when $\mathrm{x}_{2} \in\left[\underline{\mathrm{x}}, \mathrm{x}_{1}\right]$;

ii) $<\hat{\pi}_{0}^{\mathrm{P}}\left(\mathrm{x}_{2}\right)$ when $\mathrm{x}_{2} \in\left[\mathrm{x}_{1}, \min \left\{\overline{\mathrm{x}}, \mathrm{x}_{1}+2 \mathrm{~K}\right\}\right]$;

iii) $<\hat{\pi}_{0}^{\mathrm{P}}\left(\mathrm{x}_{2}\right)$ when $\mathrm{x}_{2} \in\left(\min \left\{\overline{\mathrm{x}}, \mathrm{x}_{1}+2 \mathrm{~K}\right\}, \overline{\mathrm{x}}\right]$ (if non-empty).

Therefore, there will be no general agreement among $\mathrm{P}_{1}, \mathrm{P}_{2}$ and $\mathrm{D}$ as to whether an MFN is preferred: the adoption of an MFN clause is not Pareto-superior for all types of litigants. Moreover, this also means that the expected payoff to $\mathrm{P}_{2}$ under an MFN (that is, taking the expectation of $\hat{\pi}_{2}^{\mathrm{P}}\left(\mathrm{x}_{2} ; \mathrm{x}_{1}\right)$ with respect to $\left.\mathrm{x}_{2}\right)$ is strictly lower than the expected payoff to $\mathrm{P}_{2}$ without the MFN.

However, if we consider an alternative measure of welfare, expected trial costs, it is surprising that an MFN can actually reduce expected trial costs both for $\mathrm{D}$ and for $\mathrm{P}_{2}$. Proposition 6, which is proved in the Appendix, indicates that if $F(\bullet)$ is the uniform distribution, then the expected trial costs generated by $\mathrm{P}_{2}$ and $\mathrm{D}$ are strictly lower (whenever $\mathrm{x}_{1}<\overline{\mathrm{x}}$ ) if there is an MFN in a settlement between $P_{1}$ and $D$ than if there were no MFN. Thus, for an open set of distributions sufficiently close to the uniform, expected trial costs for $\mathrm{P}_{2}$ and D are lowered when an MFN is employed.

Proposition 6. Given a first-stage settlement with type $\mathrm{x}_{1}<\overline{\mathrm{x}}$, if $\mathrm{F}(\bullet)$ is the uniform distribution then the second-stage expected trial costs under an MFN, $\mathrm{K} \int \hat{\mathrm{r}}_{2}\left(\mathrm{x}_{2} ; \mathrm{x}_{1}\right) \mathrm{dF}\left(\mathrm{x}_{2}\right)$, are 
strictly less than the second-stage expected trial costs without an MFN, $\mathrm{K} \int \hat{\mathrm{r}}_{0}\left(\mathrm{x}_{2}\right) \mathrm{dF}\left(\mathrm{x}_{2}\right)$, where both integrals are over $\mathrm{x}_{2} \in[\underline{\mathrm{x}}, \overline{\mathrm{x}}]$.

This is possible because an MFN creates both a direct and an indirect (equilibrium) effect on the likelihood that a later plaintiff type's demand is rejected. When an MFN results in a higher probability of rejection for a given demand made by a later plaintiff (the direct effect), it also moderates the demand that later plaintiff types make (the indirect, or equilibrium, effect). It is the composition of these two effects that determines whether a later plaintiff type's demand is more or less likely to be rejected under an MFN. For some later plaintiff types, these more moderate demands are rejected less often, but for the highest types these more moderate demands are rejected more often. Under a uniform distribution, the expected probability of trial in the later suit declines. We also know that when $\mathrm{F}(\bullet)$ is the uniform distribution, $\hat{\mathrm{r}}_{1}\left(\mathrm{x}_{1}\right)<\hat{\mathrm{r}}_{0}\left(\mathrm{x}_{1}\right)$; that is, $\mathrm{P}_{1}$ 's expected trial costs are also strictly lower with an MFN. Thus, total expected trial costs (for all litigants) are lower when an MFN is used.

What has happened here? Without an MFN incomplete information results in an inefficiency wherein trials sometimes occur. In both suits, $\mathrm{D}$ is fully extracted, so any gains for $\mathrm{P}_{1}$ must come out of any reduction in expected trial costs and any reduction in $\mathrm{P}_{2}$ 's take from bargaining. The presence of an MFN makes $\mathrm{P}_{2}$ moderate her demand if $\mathrm{x}_{2}>\mathrm{x}_{1}$; this moderation means that low types of $\mathrm{P}_{2}$ (those such that $\left.\mathrm{x}_{2} \leq \mathrm{x}_{1}\right)$ are unaffected but high types $\left(\mathrm{x}_{2}>\mathrm{x}_{1}\right)$ are worse off. $\mathrm{P}_{1}$ further benefits "twice" from the MFN by getting an extra payment $\left(g\left(\mathrm{~S}_{1}{ }^{*}\left(\mathrm{x}_{1}\right)\right)\right.$ if $\mathrm{D}$ settles with $\mathrm{P}_{2}$ and if $\mathrm{x}_{2}>\mathrm{x}_{1}$. First, there is the direct payment, which occurs with positive probability. Second, the presence of this extra source of income for $\mathrm{P}_{1}$ also improves her credibility, thereby further reducing the need for $\mathrm{D}$ to reject $\mathrm{P}_{1}$ 's demand in order to deter mimicry by low types of $\mathrm{P}_{1}$. Since $\mathrm{P}_{2}$ is never 
better off with an MFN and, under conditions discussed above, her expected trial costs are reduced, the fact that D is fully extracted with or without an MFN means that there is a positive expected transfer from $\mathrm{P}_{2}$ to $\mathrm{P}_{1}$ when an MFN has been employed. ${ }^{13}$ Thus, the inclusion of an MFN provision in the agreement between $\mathrm{P}_{1}$ and $\mathrm{D}$ potentially allows $\mathrm{P}_{1}$ to exploit future agreements that $\mathrm{D}$ will enter into with similarly situated (i.e., associated with the same distribution of damages) plaintiffs.

\section{Discussion and Conclusions}

It is worth summarizing how these results compare with those of Spier (forthcoming, and 2002), and how these models may inform judicial decision-making with respect to MFN clauses. Recall that, using a model in which an uninformed defendant negotiates simultaneously with a continuum of plaintiffs (which emphasizes the potential for costly delay), Spier finds that an MFN: (1) is always beneficial for the defendant; (2) can either hurt (or leave unaffected) or benefit (or leave unaffected) the plaintiffs, meaning that an MFN does not simultaneously hurt some plaintiffs and benefit others; and (3) can either raise or lower the overall extent of settlement, but all settlement is shifted into the first period, thus saving delay costs. As long as the saved delay costs exceed any equilibrium increase in trial costs, an MFN saves on total expected delay and trial costs. In particular, if damages are uniformly-distributed, then an MFN provides a Pareto improvement.

13 Aghion and Bolton (1987) show that an incumbent seller can use stipulated damages in a contract with a buyer to extract rent from an entering seller, thereby deterring some efficient entry. Generally, their optimal contract requires stipulated damages to exceed actual harm due to a breach. In American courts, stipulated damages in excess of actual harm are called a "penalty" and are generally not enforced (Rea, 1998, and Cooter and Ulen, 2000). The Aghion and Bolton argument suggests one reason why courts should not enforce such penalties. MFNs, on the other hand, are now generally enforced (or their non-enforcement is because subsequent litigants are viewed by the Court as bargaining under substantially dissimilar circumstances). 
The extent of trial is exactly the same, but there are no delay costs; all the savings in delay costs accrue to the defendant, leaving the plaintiffs exactly as well off as without an MFN.

In contrast, when informed plaintiffs negotiate sequentially with the same defendant (which emphasizes the early plaintiff's ability to exploit future settlements), we find that an MFN: (1) leaves the defendant unaffected; (2) always harms (or leaves unaffected) the later plaintiff, while the early plaintiff is at least as well off for having this option (since the early plaintiff can elect not to include an MFN in her settlement demand); and (3) the general effect of an MFN on the extent of settlement is indeterminate. Thus, an MFN can never provide a Pareto improvement in this model. However, if damages are uniformly-distributed, then an MFN reduces the overall likelihood of trial (and thus expected trial costs) in both the early and later suits; moreover, every type of early plaintiff would prefer to include an MFN in her settlement offer to the defendant. Thus, an MFN can be implemented by an early plaintiff in order to exploit a future settlement between the defendant and a later plaintiff. Despite this essentially redistributive motive, this use of an MFN can reduce the expected social costs associated with trials.

As discussed above, an MFN can reduce the expected trial costs in the second suit because of its moderating effect on demands made by $\mathrm{P}_{2}$ that exceed $\mathrm{P}_{1}$ 's demand. With respect to an early plaintiff, the prospect of a future rebate if the MFN is triggered makes this plaintiff less willing to risk trial by inflating her demand, thus providing increased incentives for revelation. As a consequence, any given demand by this plaintiff can be rejected with a lower probability.

Interestingly, both bilateral and multilateral bargaining motivations for MFN can coexist in the same general case; for instance, the tobacco case has both elements. The early settlements, involving Mississippi, Florida, and Texas, seem designed (by the settling states) to exploit possible 
future settlements. Here the MFNs were triggered and each of these states did quite well, thanks to Minnesota's settlement. Mississippi received a payment of $\$ 550$ million on top of their original settlement of $\$ 3.6$ billion; Florida received a payment $\$ 1.8$ billion on top of their original settlement of $\$ 11.3$ billion; and Texas received a payment $\$ 2.3$ billion on top of their original settlement of $\$ 15.3$ billion (see Spier, forthcoming, and Viscusi, 2002, p. 37). On the other hand, the Master Settlement Agreement also includes an MFN, presumably to keep all the remaining states in that agreement, thereby eliminating further delay. Thus, MFN clauses were used both to exploit future agreements and to bring about closure.

What guidance can these models provide for a judge who must decide whether to permit and/or enforce an MFN? If a judge's primary concern is with reducing expected trial costs, then both of these models suggest that MFNs are likely (though not guaranteed) to improve things, and it may not be important to determine whether the circumstances of the case are more consistent with one type of model or the other. On the other hand, if equity is an important consideration, then a judge should be especially skeptical of the proposed MFN if bargaining seems likely to be sequential and the (early) plaintiff has substantial bargaining power. This judicial choice also seems to turn on the issue of bilateral versus multilateral agreements in contexts where there are likely to be multiple litigants. A judge who is certifying a bilateral settlement in circumstances wherein there is likely to be further litigation by other parties needs to be convinced that overall social costs would be sufficiently reduced by the use of an MFN to compensate for likely distributional inequities. Alternatively, when all parties seem to be present, judges should expect that the question of enforcing an MFN lies more with the benefits of inducing quick settlement. Perhaps there really is safety in numbers. 


\section{Appendix}

This Appendix contains the proofs of Propositions $1-6$ and auxiliary results. The proofs of Propositions 1- 3 verify that the strategies and beliefs provided in the text constitute a revealing equilibrium in their respective contexts. The proofs of uniqueness can be constructed as in Reinganum and Wilde (1986), and are omitted.

Proof of Proposition 1. To verify that these strategies and beliefs provide a revealing equilibrium, we demonstrate that (1.A) $\mathrm{r}_{0}{ }^{*}(\mathrm{~S})$ is an optimal strategy for $\mathrm{D}$, given the beliefs $\mathrm{b}_{0}{ }^{*}(\mathrm{~S}) ;(1 . \mathrm{B}) \mathrm{S}_{0}{ }^{*}(\mathrm{x})$ is an optimal strategy for $\mathrm{P}$, given $\mathrm{r}_{0} *(\mathrm{~S})$; and (1.C) the beliefs are correct: $\mathrm{b}_{0} *\left(\mathrm{~S}_{0} *(\mathrm{x})\right)=\mathrm{x}$ for $\mathrm{x} \in$ $[\underline{x}, \bar{x}]$.

Proof of (1.A). Given the beliefs $b_{0} *(S)$, upon observing the demand $S \in[\underline{S}, \bar{S}]$, D expects to pay $\mathrm{b}_{0}{ }^{*}(\mathrm{~S})+\mathrm{k}^{\mathrm{D}}=\mathrm{S}$ if he rejects the demand $\mathrm{S}$ and $\mathrm{D}$ expects to pay $\mathrm{S}$ if he accepts the demand $\mathrm{S}$, so he is indifferent. Hence he is willing to randomize as specified by $r_{0}{ }^{*}(\mathrm{~S})$. A demand $\mathrm{S}>\overline{\mathrm{S}}$ is believed to have come from type $\overline{\mathrm{x}}$ so it is optimal for $\mathrm{D}$ to reject it (and pay $\overline{\mathrm{x}}+\mathrm{k}^{\mathrm{D}}$ at trial) rather than to accept it (and pay $S>\bar{S}=\bar{x}+k^{D}$ in settlement). Finally, a demand $S<\underline{S}$ is believed to have come from type $\underline{x}$ so it is optimal for $\mathrm{D}$ to accept it (and pay $\mathrm{S}<\underline{\mathrm{S}}=\underline{\mathrm{x}}+\mathrm{k}^{\mathrm{D}}$ in settlement) rather than to reject it (and pay $\underline{\mathrm{x}}+\mathrm{k}^{\mathrm{D}}$ at trial).

Proof of (1.B). Given the strategy $r_{0} *(S)$, a $P$ of type $x$ demanding $S$ anticipates a payoff of $\pi^{\mathrm{P}}(\mathrm{S})$ $=\mathrm{r}_{0} *(\mathrm{~S})\left(\mathrm{x}-\mathrm{k}^{\mathrm{P}}\right)+\left(1-\mathrm{r}_{0} *(\mathrm{~S})\right) \mathrm{S}$. First note that any strategy $\mathrm{S}<\underline{\mathrm{S}}$ is dominated by $\mathrm{S}=\underline{\mathrm{S}}$ since both are accepted for sure. Moreover, any strategy $\mathrm{S}>\overline{\mathrm{S}}$ is dominated by $\mathrm{S}=\overline{\mathrm{S}}$ since the former generates a payoff of $\mathrm{x}-\mathrm{k}^{\mathrm{P}}$ for sure, while the latter generates a convex combination of $\overline{\mathrm{S}}>\mathrm{x}-\mathrm{k}^{\mathrm{P}}$ and $\mathrm{x}-\mathrm{k}^{\mathrm{P}}$. Thus, the optimal demand must belong to $[\underline{\mathrm{S}}, \overline{\mathrm{S}}]$. Maximizing the expression $\mathrm{r}_{0} *(\mathrm{~S})(\mathrm{x}-$ $\left.\mathrm{k}^{\mathrm{P}}\right)+\left(1-\mathrm{r}_{0} *(\mathrm{~S})\right) \mathrm{S}$ with respect to $\mathrm{S}$ yields the first-order condition: $-\left\{\left[\mathrm{S}-\mathrm{x}+\mathrm{k}^{\mathrm{P}}\right] / \mathrm{K}\right\} \exp \{-(\mathrm{S}-\underline{\mathrm{S}}) / \mathrm{K}$ $+\exp \left\{-(\mathrm{S}-\underline{\mathrm{S}}) / \mathrm{K}=0\right.$, which has the unique solution $\mathrm{S}_{0} *(\mathrm{x})=\mathrm{x}+\mathrm{k}^{\mathrm{D}}$. To see that this is a local maximum, note that the second-order condition for a maximum is $\left\{\left[\mathrm{S}-\mathrm{x}+\mathrm{k}^{\mathrm{P}}-2 \mathrm{~K}\right] / \mathrm{K}^{2}\right\} \exp \{-(\mathrm{S}-$ $\underline{\mathrm{S}}) / \mathrm{K} \leq 0$, which is satisfied at $\mathrm{S}_{0} *(\mathrm{x})=\mathrm{x}+\mathrm{k}^{\mathrm{D}}$. If another maximum were to exist on the boundary (that is, at $\underline{\mathrm{S}}$ or $\overline{\mathrm{S}}$ ), there would have to be a local minimum between it and $\mathrm{S}_{0}{ }^{*}(\mathrm{x})$, but no other interior stationary point exists, since $\mathrm{S}_{0} *(\mathrm{x})$ is the unique interior solution to the first-order condition. Thus $\mathrm{S}_{0}{ }^{*}(\mathrm{x})$ provides the global maximum to $\mathrm{P}$ 's payoff.

Proof of (1.C). Substitution yields $\mathrm{b}_{0} *\left(\mathrm{~S}_{0} *(\mathrm{x})\right)=\mathrm{S}_{0} *(\mathrm{x})-\mathrm{k}^{\mathrm{D}}=\mathrm{x}+\mathrm{k}^{\mathrm{D}}-\mathrm{k}^{\mathrm{D}}=\mathrm{x}$ for $\mathrm{x} \in[\underline{\mathrm{x}}, \overline{\mathrm{x}}]$; thus the beliefs are correct in equilibrium. Moreover, the equilibrium strategies are robust to arbitrary out-of-equilibrium beliefs. QED

Proof of Proposition 2. The strategy of proof is similar to that for Proposition 1 . To verify that these strategies and beliefs provide a revealing equilibrium, we demonstrate that (2.A) $r_{2} *\left(S_{2} ; S_{1}\right)$ is an optimal strategy for $\mathrm{D}$, given the beliefs $\mathrm{b}_{2} *\left(\mathrm{~S}_{2} ; \mathrm{S}_{1}\right) ;(2 . \mathrm{B}) \mathrm{S}_{2} *\left(\mathrm{x}_{2} ; \mathrm{S}_{1}\right)$ is an optimal strategy for $\mathrm{P}_{2}$, given $\mathrm{r}_{2} *\left(\mathrm{~S}_{2} ; \mathrm{S}_{1}\right)$; and (2.C) the beliefs are correct: $\mathrm{b}_{2}{ }^{*}\left(\mathrm{~S}_{2} *\left(\mathrm{x}_{2} ; \mathrm{S}_{1}\right) ; \mathrm{S}_{1}\right)=\mathrm{x}_{2}$ for $\mathrm{x}_{2} \in[\underline{\mathrm{x}}, \overline{\mathrm{x}}]$.

Proof of (2.A). Recall that if D settles with $\mathrm{P}_{2}$ at $\mathrm{S}_{2}>\mathrm{S}_{1}$, then D pays $\mathrm{S}_{2}$ to $\mathrm{P}_{2}$ and the amount $\mathrm{S}_{2}$ - 
$\mathrm{S}_{1}$ to $\mathrm{P}_{1}$, while if $\mathrm{D}$ settles with $\mathrm{P}_{2}$ at $\mathrm{S}_{2} \leq \mathrm{S}_{1}$, then $\mathrm{D}$ simply pays $\mathrm{S}_{2}$ to $\mathrm{P}_{2}$. Given the beliefs $\mathrm{b}_{2} *\left(\mathrm{~S}_{2} ; \mathrm{S}_{1}\right)$, upon observing a demand $\mathrm{S}_{2} \in\left[\underline{\mathrm{S}}, \mathrm{S}_{1}\right], \mathrm{D}$ expects to pay $\mathrm{b}_{2} *\left(\mathrm{~S}_{2} ; \mathrm{S}_{1}\right)+\mathrm{k}^{\mathrm{D}}=\mathrm{S}_{2}-\mathrm{k}^{\mathrm{D}}+\mathrm{k}^{\mathrm{D}}$ $=S_{2}$ if he rejects the demand $S_{2}$ and $D$ expects to pay $S_{2}$ if he accepts the demand $S_{2}$, so he is indifferent. Hence he is willing to randomize as specified by $r_{2} *\left(S_{2} ; S_{1}\right)$. Upon observing a demand $\mathrm{S}_{2} \in\left[\mathrm{S}_{1}, \overline{\mathrm{S}}_{2}\left(\mathrm{~S}_{1}\right)\right]$, D expects to pay $\mathrm{b}_{2}{ }^{*}\left(\mathrm{~S}_{2} ; \mathrm{S}_{1}\right)+\mathrm{k}^{\mathrm{D}}=2 \mathrm{~S}_{2}-\mathrm{k}^{\mathrm{D}}-\mathrm{S}_{1}+\mathrm{k}^{\mathrm{D}}=2 \mathrm{~S}_{2}-\mathrm{S}_{1}$ if he rejects the demand $S_{2}$ and $D$ expects to pay $2 S_{2}-S_{1}$ if he accepts the demand $S_{2}$ (since he settles with $P_{2}$ at $S_{2}$ and rebates the difference $S_{2}-S_{1}$ to $P_{1}$ ). Thus, $D$ is indifferent, and hence is willing to randomize as specified by $r_{2} *\left(S_{2} ; S_{1}\right)$ for $S_{2} \in\left[S_{1}, S_{1}+K\right]$, and is willing to reject for $S_{2} \geq S_{1}+K$. A demand $\mathrm{S}_{2}>\overline{\mathrm{S}}_{2}\left(\mathrm{~S}_{1}\right)$ is believed to have come from type $\overline{\mathrm{x}}$ so it is optimal for $\mathrm{D}$ to reject it (and pay $\overline{\mathrm{x}}+\mathrm{k}^{\mathrm{D}}$ at trial) rather than to accept it (and pay $2 \mathrm{~S}_{2}-\mathrm{S}_{1}>2 \overline{\mathrm{S}}_{2}\left(\mathrm{~S}_{1}\right)-\mathrm{S}_{1}=\overline{\mathrm{x}}+\mathrm{k}^{\mathrm{D}}$ in settlement). Finally, a demand $\mathrm{S}_{2}<\underline{\mathrm{S}}$ is believed to have come from type $\underline{\mathrm{x}}$ so it is optimal for $\mathrm{D}$ to accept it (and pay $\mathrm{S}_{2}$ $<\underline{\mathrm{S}}=\underline{\mathrm{x}}+\mathrm{k}^{\mathrm{D}}$ in settlement) rather than to reject it (and pay $\underline{\mathrm{x}}+\mathrm{k}^{\mathrm{D}}$ at trial).

Proof of (2.B). Given the strategy $\mathrm{r}_{2} *\left(\mathrm{~S}_{2} ; \mathrm{S}_{1}\right)$, a $\mathrm{P}_{2}$ of type $\mathrm{x}_{2}$ demanding $\mathrm{S}_{2}$ anticipates a payoff of $\pi_{2}{ }^{\mathrm{P}}\left(\mathrm{S}_{2} ; \mathrm{S}_{1}\right)=\mathrm{r}_{2} *\left(\mathrm{~S}_{2} ; \mathrm{S}_{1}\right)\left(\mathrm{x}_{2}-\mathrm{k}^{\mathrm{P}}\right)+\left(1-\mathrm{r}_{2} *\left(\mathrm{~S}_{2} ; \mathrm{S}_{1}\right)\right) \mathrm{S}_{2}$. This payoff function is everywhere continuous in $\mathrm{S}_{2}$, though there are some points of non-differentiability where the function $\mathrm{r}_{2}{ }^{*}$ makes transitions. First note that any strategy $\mathrm{S}_{2}<\underline{\mathrm{S}}$ is dominated by $\mathrm{S}_{2}=\underline{\mathrm{S}}$ since both are accepted for sure. Moreover, any strategy $S_{2}>\bar{S}_{2}\left(S_{1}\right)$ is (at least weakly) dominated by $S_{2}=\bar{S}_{2}\left(S_{1}\right)$ since the former generates a payoff of $x_{2}-k^{p}$ for sure, while the latter generates either $x_{2}-k^{P}$ for sure $\left(\right.$ if $\bar{S}_{2}\left(S_{1}\right) \geq S_{1}$ $+\mathrm{K}$ ) or a convex combination of $\mathrm{x}_{2}-\mathrm{k}^{\mathrm{P}}$ and $\overline{\mathrm{S}}_{2}\left(\mathrm{~S}_{1}\right)$ (if $\overline{\mathrm{S}}_{2}\left(\mathrm{~S}_{1}\right)<\mathrm{S}_{1}+\mathrm{K}$, in which case $\overline{\mathrm{S}}_{2}\left(\mathrm{~S}_{1}\right)>\mathrm{x}_{2}$ $\left.\mathrm{k}^{\mathrm{P}}\right)$. Thus, the optimal demand must belong to $\left[\underline{\mathrm{S}}, \overline{\mathrm{S}}_{2}\left(\mathrm{~S}_{1}\right)\right]$.

In order to determine $\mathrm{P}_{2}$ 's optimal demand, we must find the best demand on each of the branches of $\mathrm{P}_{2}$ 's payoff (corresponding to the three branches of $\mathrm{r}_{2}{ }^{*}\left(\mathrm{~S}_{2} ; \mathrm{S}_{1}\right)$ ) and choose between them. Notice that $r_{2} *\left(S_{2} ; S_{1}\right)=r_{0} *\left(S_{2}\right)$ for $S_{2} \leq S_{1}$. Thus, type $x_{2}$ 's best demand in $\left[\underline{S}, S_{1}\right]$ is given by $\mathrm{S}_{2} *=\mathrm{x}_{2}+\mathrm{k}_{\mathrm{D}}$, provided this does not exceed $\mathrm{S}_{1}$; otherwise type $\mathrm{x}_{2}$ 's best demand in $\left[\underline{\mathrm{S}}, \mathrm{S}_{1}\right]$ is given by $\mathrm{S}_{2} *=\mathrm{S}_{1}$. Similarly, type $\mathrm{x}_{2}$ 's best (interior) demand in $\left[\mathrm{S}_{1}, \mathrm{~S}_{1}+\mathrm{K}\right]$ satisfies the first-order condition $\left\{\left[\mathrm{S}_{1}+\mathrm{K}-\mathrm{S}_{2}\right] / \mathrm{K}\right\} \exp \left\{-\left(\mathrm{S}_{1}-\underline{\mathrm{S}}\right) / \mathrm{K}\right\}-\left\{\left[\mathrm{S}_{2}-\mathrm{x}_{2}+\mathrm{k}^{\mathrm{P}}\right] / \mathrm{K}\right\} \exp \left\{-\left(\mathrm{S}_{1}-\underline{\mathrm{S}}\right) / \mathrm{K}\right\}=0$, which has the unique solution $\mathrm{S}_{2}{ }^{*}=\left(\mathrm{x}_{2}+\mathrm{k}^{\mathrm{D}}+\mathrm{S}_{1}\right) / 2$. To see that this is a maximum, note that the second-order condition for a maximum is $\{-2 / \mathrm{K}\} \exp \left\{-\left(\mathrm{S}_{1}-\underline{\mathrm{S}}\right) / \mathrm{K}\right\} \leq 0$, which is clearly satisfied. Thus, $\mathrm{S}_{2}{ }^{*}=$ $\left(\mathrm{x}+\mathrm{k}^{\mathrm{D}}+\mathrm{S}_{1}\right) / 2$ is type $\mathrm{x}_{2}$ 's best demand in $\left[\mathrm{S}_{1}, \mathrm{~S}_{1}+\mathrm{K}\right]$ provided it is at least $\mathrm{S}_{1}$ and does not exceed $\mathrm{S}_{1}+\mathrm{K}$; otherwise type $\mathrm{x}_{2}$ 's best demand in $\left[\mathrm{S}_{1}, \mathrm{~S}_{1}+\mathrm{K}\right]$ is either $\mathrm{S}_{2} *=\mathrm{S}_{1}$ or $\mathrm{S}_{2}{ }^{*}=\mathrm{S}_{1}+\mathrm{K}$. Type $\mathrm{x}_{2}$ is indifferent among all demands that exceed $\mathrm{S}_{1}+\mathrm{K}$, as they are all rejected with certainty; thus, if type $\mathrm{x}_{2}$ 's best demand in $\left[\mathrm{S}_{1}, \mathrm{~S}_{1}+\mathrm{K}\right]$ is $\mathrm{S}_{1}+\mathrm{K}$, then this type is actually indifferent among all demands that will be rejected with certainty.

Consider $\mathrm{P}_{2}$ types with $\mathrm{x}_{2} \in\left[\underline{\mathrm{x}}, \mathrm{S}_{1}-\mathrm{k}^{\mathrm{D}}\right]$. Type $\mathrm{x}_{2}$ 's best demand in $\left[\underline{\mathrm{S}}, \mathrm{S}_{1}\right]$ is $\mathrm{S}_{2}{ }^{*}=\mathrm{x}_{2}+\mathrm{k}_{\mathrm{D}}$, while type $\mathrm{x}_{2}$ 's best demand in $\left[\mathrm{S}_{1}, \mathrm{~S}_{1}+\mathrm{K}\right]$ is $\mathrm{S}_{1}$ since (i) the aforementioned "interior" solution is not interior to the interval; that is, $\mathrm{S}_{2} *=\left(\mathrm{x}_{2}+\mathrm{k}^{\mathrm{D}}+\mathrm{S}_{1}\right) / 2 \leq \mathrm{S}_{1}$, and (ii) the payoff associated with $\mathrm{S}_{2}$ $=\mathrm{S}_{1}+\mathrm{K}$ is $\mathrm{x}_{2}-\mathrm{k}^{\mathrm{P}}$, while that associated with $\mathrm{S}_{2}=\mathrm{S}_{1}$ is $\mathrm{S}_{1}\left[\exp \left\{-\left(\mathrm{S}_{1}-\underline{\mathrm{S}}\right) / \mathrm{K}\right\}\right]+\left[1-\exp \left\{-\left(\mathrm{S}_{1}-\right.\right.\right.$ $\underline{\mathrm{S}}) / \mathrm{K}]\left(\mathrm{x}_{2}-\mathrm{k}^{\mathrm{P}}\right)>\mathrm{x}_{2}-\mathrm{k}^{\mathrm{P}}$ for $\mathrm{x}_{2} \in\left[\underline{\mathrm{x}}, \mathrm{S}_{1}-\mathrm{k}^{\mathrm{D}}\right]$. Thus, $\mathrm{S}_{2} *\left(\mathrm{x}_{2} ; \mathrm{S}_{1}\right)=\mathrm{x}_{2}+\mathrm{k}^{\mathrm{D}}$ for $\mathrm{x}_{2} \in\left[\underline{\mathrm{x}}, \mathrm{S}_{1}-\mathrm{k}^{\mathrm{D}}\right]$. Now consider $\mathrm{P}_{2}$ types with $\mathrm{x}_{2} \in\left[\mathrm{S}_{1}-\mathrm{k}^{\mathrm{D}}, \overline{\mathrm{x}}\right]$. Type $\mathrm{x}_{2}{ }^{\prime} \mathrm{S}$ best demand in $\left[\underline{\mathrm{S}}, \mathrm{S}_{1}\right]$ is $\mathrm{S}_{2}{ }^{*}=\mathrm{S}_{1}$ since the "interior" solution is not interior to the interval (that is, $\mathrm{S}_{2}{ }^{*}=\mathrm{x}_{2}+\mathrm{k}_{\mathrm{D}} \geq \mathrm{S}_{1}$ ), while type $\mathrm{x}_{2}$ 's best 
demand in $\left[\mathrm{S}_{1}, \mathrm{~S}_{1}+\mathrm{K}\right]$ is $\mathrm{S}_{2}{ }^{*}=\min \left\{\left(\mathrm{x}_{2}+\mathrm{k}^{\mathrm{D}}+\mathrm{S}_{1}\right) / 2, \mathrm{~S}_{1}+\mathrm{K}\right\}$. Since $\mathrm{P}_{2}$ 's payoff is continuous, it follows that $\mathrm{S}_{2} *\left(\mathrm{x}_{2} ; \mathrm{S}_{1}\right)=\min \left\{\left(\mathrm{x}_{2}+\mathrm{k}^{\mathrm{D}}+\mathrm{S}_{1}\right) / 2, \mathrm{~S}_{1}+\mathrm{K}\right\}$ for $\mathrm{x}_{2} \in\left[\mathrm{S}_{1}-\mathrm{k}^{\mathrm{D}}, \overline{\mathrm{x}}\right]$. Let $\tilde{\mathrm{x}}_{2}\left(\mathrm{~S}_{1}\right) \equiv \mathrm{S}_{1}+\mathrm{K}+$ $k^{P}$. This is the $P_{2}$-type who is just indifferent between settling at the demand $S_{2}=\left(x_{2}+k^{D}+S_{1}\right) / 2$ versus demanding $\mathrm{S}_{1}+\mathrm{K}$ and going to trial (and receiving $\mathrm{x}_{2}-\mathrm{k}^{\mathrm{P}}$ ). Thus, type $\mathrm{x}_{2}{ }^{\prime}$ s optimal demand is uniquely defined by $\mathrm{S}_{2} *\left(\mathrm{x}_{2} ; \mathrm{S}_{1}\right)=\left(\mathrm{x}_{2}+\mathrm{k}^{\mathrm{D}}+\mathrm{S}_{1}\right) / 2$ for $\mathrm{x}_{2} \in\left[\mathrm{S}_{1}-\mathrm{k}^{\mathrm{D}}, \widetilde{\mathrm{x}}_{2}\left(\mathrm{~S}_{1}\right)\right]$, and those types $\mathrm{x}_{2} \in$ $\left(\widetilde{\mathrm{x}}_{2}\left(\mathrm{~S}_{1}\right), \overline{\mathrm{x}}\right]$ are indifferent among all demands that exceed $\mathrm{S}_{1}+\mathrm{K}$. Thus, those types $\mathrm{x}_{2} \in\left(\widetilde{\mathrm{x}}_{2}\left(\mathrm{~S}_{1}\right), \overline{\mathrm{x}}\right]$ are willing to demand according to the function $\mathrm{S}_{2} *\left(\mathrm{x}_{2} ; \mathrm{S}_{1}\right)=\left(\mathrm{x}_{2}+\mathrm{k}^{\mathrm{D}}+\mathrm{S}_{1}\right) / 2$, even though this demand will result in rejection for sure (the nearest demand with a positive probability of acceptance is $S_{1}+K-\epsilon$, but this is worse than trial for $\left.x_{2} \in\left(\widetilde{x}_{2}\left(S_{1}\right), \bar{x}\right]\right)$.

Proof of (2.C). For $\mathrm{x}_{2} \in\left[\underline{\mathrm{x}}, \mathrm{S}_{1}-\mathrm{k}^{\mathrm{D}}\right]$, substitution yields $\mathrm{b}_{2} *\left(\mathrm{~S}_{2} *\left(\mathrm{x}_{2} ; \mathrm{S}_{1}\right)\right)=\mathrm{S}_{2} *\left(\mathrm{x}_{2} ; \mathrm{S}_{1}\right)-\mathrm{k}^{\mathrm{D}}=\mathrm{x}_{2}+\mathrm{k}^{\mathrm{D}}-$ $\mathrm{k}^{\mathrm{D}}=\mathrm{x}_{2}$. Similarly, for $\mathrm{x}_{2} \in\left[\mathrm{S}_{1}-\mathrm{k}^{\mathrm{D}}, \overline{\mathrm{x}}\right]$, substitution yields $\mathrm{b}_{2}{ }^{*}\left(\mathrm{~S}_{2}{ }^{*}\left(\mathrm{x}_{2} ; \mathrm{S}_{1}\right)\right)=2 \mathrm{~S}_{2}{ }^{*}\left(\mathrm{x}_{2} ; \mathrm{S}_{1}\right)-\mathrm{k}^{\mathrm{D}}-\mathrm{S}_{1}$ $=2\left(\mathrm{x}_{2}+\mathrm{k}^{\mathrm{D}}+\mathrm{S}_{1}\right) / 2-\mathrm{k}^{\mathrm{D}}-\mathrm{S}_{1}=\mathrm{x}_{2}$.

We say this equilibrium is "essentially" unique because types $\mathrm{x}_{2} \in\left(\widetilde{\mathrm{x}}_{2}\left(\mathrm{~S}_{1}\right), \overline{\mathrm{x}}\right]$ are indifferent among demands that are rejected and hence could be assigned to a different revealing (i.e., monotonic) demand function that involves demands that are rejected. QED

Proof of claims regarding the function $\mathrm{g}\left(\mathrm{S}_{1}\right)$.

Recall that $\mathrm{T}\left(\mathrm{S}_{1}\right) \equiv\left[\mathrm{S}_{1}-\mathrm{k}^{\mathrm{D}}, \min \left\{\overline{\mathrm{x}}, \mathrm{S}_{1}+\mathrm{K}+\mathrm{k}^{\mathrm{P}}\right\}\right]$. This interval is non-degenerate as long as $\mathrm{S}_{1}<$ $\overline{\mathrm{S}}=\overline{\mathrm{x}}+\mathrm{k}^{\mathrm{D}}$, while $\mathrm{T}(\overline{\mathrm{S}})=[\overline{\mathrm{x}}, \overline{\mathrm{x}}]$.

(1) To see that $g\left(S_{1}\right)>0$ for all $S_{1} \in[\underline{S}, \bar{S})$ and $g(\bar{S})=0$, simply note that the integrand is a positive number for all $\mathrm{x}_{2} \in \operatorname{int} \mathrm{T}\left(\mathrm{S}_{1}\right)$. Since this interior is non-empty for $\mathrm{S}_{1} \in[\underline{\mathrm{S}}, \overline{\mathrm{S}})$ (and empty for $\mathrm{S}_{1}=\overline{\mathrm{S}}$ ), the claimed results follow.

(2) To see that $1+\mathrm{g}^{\prime}\left(\mathrm{S}_{1}\right)>0$ for all $\mathrm{S}_{1} \in[\underline{\mathrm{S}}, \overline{\mathrm{S}}]$, let $\mathrm{h}\left(\mathrm{S}_{1} ; \mathrm{x}_{2}\right) \equiv\left(\mathrm{x}_{2}+\mathrm{k}^{\mathrm{D}}-\mathrm{S}_{1}\right)\left(\mathrm{S}_{1}+\mathrm{K}+\mathrm{k}^{\mathrm{P}}-\mathrm{x}_{2}\right) / 4 \mathrm{~K}$, and write $\mathrm{g}\left(\mathrm{S}_{1}\right) \equiv \int \mathrm{h}\left(\mathrm{S}_{1} ; \mathrm{x}_{2}\right) \exp \left\{-\left(\mathrm{S}_{1}-\underline{\mathrm{S}}\right) / \mathrm{K}\right\} \mathrm{f}\left(\mathrm{x}_{2}\right) \mathrm{dx}$, where the integral is taken over $\mathrm{x}_{2} \in \mathrm{T}\left(\mathrm{S}_{1}\right)$. The payment to $P_{1}$ if settlement occurs at $S_{1}$ is $S_{1}+g\left(S_{1}\right)$. The derivative of this expression is $1+$ $g^{\prime}\left(S_{1}\right)$.

$$
\mathrm{g}^{\prime}\left(\mathrm{S}_{1}\right)=\int\left[\partial \mathrm{h}\left(\mathrm{S}_{1} ; \mathrm{x}_{2}\right) / \partial \mathrm{S}_{1}-\mathrm{h}\left(\mathrm{S}_{1} ; \mathrm{x}_{2}\right) / \mathrm{K}\right] \exp \left\{-\left(\mathrm{S}_{1}-\underline{\mathrm{S}}\right) / \mathrm{K}\right\} \mathrm{f}\left(\mathrm{x}_{2}\right) \mathrm{dx} \mathrm{x}_{2},
$$

where the integral is taken over $\mathrm{x}_{2} \in \mathrm{T}\left(\mathrm{S}_{1}\right)$. The difference $\left.\partial \mathrm{h}\left(\mathrm{S}_{1} ; \mathrm{x}_{2}\right) / \partial \mathrm{S}_{1}\right)-\mathrm{h}\left(\mathrm{S}_{1} ; \mathrm{x}_{2}\right) / \mathrm{K}=\left(\mathrm{x}_{2}+\mathrm{k}^{\mathrm{D}}-\right.$ $\left.\mathrm{S}_{1}-\mathrm{K}\right) / 2 \mathrm{~K}-\left(\mathrm{x}_{2}+\mathrm{k}^{\mathrm{D}}-\mathrm{S}_{1}\right)\left(\mathrm{S}_{1}+\mathrm{K}+\mathrm{k}^{\mathrm{P}}-\mathrm{x}_{2}\right) / 4 \mathrm{~K}^{2}$, which can be simplified to $\left[\left(\mathrm{x}_{2}+\mathrm{k}^{\mathrm{D}}-\mathrm{S}_{1}\right) / 2 \mathrm{~K}\right]^{2}-.5$. Thus,

$$
\begin{aligned}
1+\mathrm{g}^{\prime}\left(\mathrm{S}_{1}\right) & =1+\int\left\{\left[\left(\mathrm{x}_{2}+\mathrm{k}^{\mathrm{D}}-\mathrm{S}_{1}\right) / 2 \mathrm{~K}\right]^{2}-.5\right\} \exp \left\{-\left(\mathrm{S}_{1}-\underline{\mathrm{S}}\right) / \mathrm{K}\right\} \mathrm{f}\left(\mathrm{x}_{2}\right) \mathrm{dx} \mathrm{x}_{2} \\
\quad= & 1-.5 \mathrm{~F}\left(\mathrm{~T}\left(\mathrm{~S}_{1}\right)\right) \exp \left\{-\left(\mathrm{S}_{1}-\underline{\mathrm{S}}\right) / \mathrm{K}\right\}+\int\left[\left(\mathrm{x}_{2}+\mathrm{k}^{\mathrm{D}}-\mathrm{S}_{1}\right) / 2 \mathrm{~K}\right]^{2} \exp \left\{-\left(\mathrm{S}_{1}-\underline{\mathrm{S}}\right) / \mathrm{K}\right\} \mathrm{f}\left(\mathrm{x}_{2}\right) \mathrm{dx} \mathrm{x}_{2},
\end{aligned}
$$

where $F\left(T\left(S_{1}\right)\right)$ is the measure of the set $T\left(S_{1}\right)$. Since .5 is strictly less than 1 and $F\left(T\left(S_{1}\right)\right)$ and $\exp \left\{-\left(S_{1}-\underline{S}\right) / K\right\}$ are less than or equal to 1 , the product of these three numbers is less than one. The 
remaining (integral) term is clearly non-negative. Thus $1+\mathrm{g}^{\prime}\left(\mathrm{S}_{1}\right)>0$ for all $\mathrm{S}_{1} \in[\underline{\mathrm{S}}, \overline{\mathrm{S}}]$.

(3) To see that $\mathrm{g}^{\prime}\left(\mathrm{S}_{1}\right)<+\infty$ for all $\mathrm{S}_{1} \in[\underline{\mathrm{S}}, \overline{\mathrm{S}}]$, note that $\left\{\left[\left(\mathrm{x}_{2}+\mathrm{k}^{\mathrm{D}}-\mathrm{S}_{1}\right) / 2 \mathrm{~K}\right]^{2}-.5\right\} \exp \left\{-\left(\mathrm{S}_{1}-\underline{\mathrm{S}}\right) / \mathrm{K}\right\}$ is bounded for all $\mathrm{S}_{1} \in[\underline{\mathrm{S}}, \overline{\mathrm{S}}]$; let $\mathrm{B}$ denote this bound. Then $\mathrm{g}^{\prime}\left(\mathrm{S}_{1}\right) \leq \mathrm{BF}\left(\mathrm{T}\left(\mathrm{S}_{1}\right)\right)<\mathrm{B}$. QED

Proof of Proposition 3. The proof follows that of Proposition 1. To verify that these strategies and beliefs provide a revealing equilibrium, we demonstrate that (3.A) $r_{1} *\left(S_{1}\right)$ is an optimal strategy for $D$, given the beliefs $b_{1} *\left(S_{1}\right)$; (3.B) $S_{1} *\left(x_{1}\right)$ is an optimal strategy for $\mathrm{P}_{1}$, given $r_{1} *\left(S_{1}\right)$; and (3.C) the beliefs are correct: $\mathrm{b}_{1} *\left(\mathrm{~S}_{1} *\left(\mathrm{x}_{1}\right)\right)=\mathrm{x}_{1}$ for $\mathrm{x}_{1} \in[\underline{\mathrm{x}}, \overline{\mathrm{x}}]$.

Proof of (3.A). Given the beliefs $b_{1} *\left(S_{1}\right)$, upon observing the demand $S_{1} \in[\underline{S}, \bar{S}]$, D expects to pay $\mathrm{b}_{1}{ }^{*}\left(\mathrm{~S}_{1}\right)+\mathrm{k}^{\mathrm{D}}+\mathrm{ECV}^{\mathrm{D}}=\mathrm{S}_{1}+\mathrm{ECV}^{\mathrm{D}}$ if he rejects the demand $\mathrm{S}_{1}$ and $\mathrm{D}$ expects to pay $\mathrm{S}_{1}+\mathrm{ECV}^{\mathrm{D}}$ if he accepts the demand $S_{1}$, so he is indifferent. Hence he is willing to randomize as specified by $\mathrm{r}_{1} *\left(\mathrm{~S}_{1}\right)$. A demand $\mathrm{S}_{1}>\overline{\mathrm{S}}$ is believed to have come from type $\overline{\mathrm{x}}$ so it is optimal for $\mathrm{D}$ to reject it (and expect to pay $\overline{\mathrm{x}}+\mathrm{k}^{\mathrm{D}}$ at trial $+\mathrm{ECV}^{\mathrm{D}}$ ) rather than to accept it (and pay $\mathrm{S}_{1}>\overline{\mathrm{S}}=\overline{\mathrm{x}}+\mathrm{k}^{\mathrm{D}}+\mathrm{ECV}^{\mathrm{D}}$ in settlement). Finally, a demand $\mathrm{S}_{1}<\underline{\mathrm{S}}$ is believed to have come from type $\underline{\mathrm{x}}$ so it is optimal for $\mathrm{D}$ to accept it (and pay $\mathrm{S}_{1}+\mathrm{ECV}^{\mathrm{D}}<\underline{\mathrm{S}}+\mathrm{ECV}^{\mathrm{D}}=\underline{\mathrm{x}}+\mathrm{k}^{\mathrm{D}}+\mathrm{ECV}^{\mathrm{D}}$ in settlement) rather than to reject it (and pay $\underline{x}+\mathrm{k}^{\mathrm{D}}$ at trial plus $\mathrm{ECV}^{\mathrm{D}}$ ).

Proof of (3.B). Given the strategy $r_{1} *\left(S_{1}\right)$, a $P_{1}$ of type $x_{1}$ demanding $S_{1}$ anticipates a payoff of $\pi_{1}^{\mathrm{P}}\left(\mathrm{S}_{1}\right)=\mathrm{r}_{1} *\left(\mathrm{~S}_{1}\right)\left(\mathrm{x}_{1}-\mathrm{k}^{\mathrm{P}}\right)+\left(1-\mathrm{r}_{1} *\left(\mathrm{~S}_{1}\right)\right)\left(\mathrm{S}_{1}+\mathrm{g}\left(\mathrm{S}_{1}\right)\right)$. Since $\mathrm{d}\left(\mathrm{S}_{1}+\mathrm{g}\left(\mathrm{S}_{1}\right)\right) / \mathrm{dS}_{1}=1+\mathrm{g}^{\prime}\left(\mathrm{S}_{1}\right)>0$, higher demands yield higher overall payments if accepted. Thus, any strategy $S_{1}<\underline{S}$ is dominated by $S_{1}$ $=\underline{\mathrm{S}}$ since both are accepted for sure. Moreover, any strategy $\mathrm{S}_{1}>\overline{\mathrm{S}}$ is dominated by $\mathrm{S}_{1}=\overline{\mathrm{S}}$ since the former generates a payoff of $\mathrm{x}-\mathrm{k}^{\mathrm{P}}$ for sure, while the latter generates a convex combination of $\mathrm{x}-\mathrm{k}^{\mathrm{P}}$ and $\overline{\mathrm{S}}+\mathrm{g}(\overline{\mathrm{S}})>\mathrm{x}-\mathrm{k}^{\mathrm{P}}$. Thus, the optimal demand must belong to $[\underline{\mathrm{S}}, \overline{\mathrm{S}}]$. Maximizing the expression $\mathrm{r}_{1} *\left(\mathrm{~S}_{1}\right)\left(\mathrm{x}_{1}-\mathrm{k}^{\mathrm{P}}\right)+\left(1-\mathrm{r}_{1} *\left(\mathrm{~S}_{1}\right)\right)\left(\mathrm{S}_{1}+\mathrm{g}\left(\mathrm{S}_{1}\right)\right)$ with respect to $\mathrm{S}_{1}$ yields the first-order condition:

$$
\begin{gathered}
-\left(\mathrm{S}_{1}+\mathrm{g}\left(\mathrm{S}_{1}\right)-\mathrm{x}_{1}+\mathrm{k}^{\mathrm{P}}\right)\left[\left(1+\mathrm{g}^{\prime}\left(\mathrm{S}_{1}\right)\right) /\left(\mathrm{K}+\mathrm{g}\left(\mathrm{S}_{1}\right)\right] \exp \left\{-\int_{\left[\underline{\mathrm{S}}, \mathrm{S}_{1}\right]}\left(1+\mathrm{g}^{\prime}(\mathrm{t})\right) /(\mathrm{K}+\mathrm{g}(\mathrm{t})) \mathrm{dt}\right\}\right. \\
+\left(1+\mathrm{g}^{\prime}\left(\mathrm{S}_{1}\right)\right) \exp \left\{-\int_{\left[\underline{\mathrm{S}}, \mathrm{S}_{1}\right]}\left(1+\mathrm{g}^{\prime}(\mathrm{t})\right) /(\mathrm{K}+\mathrm{g}(\mathrm{t})) \mathrm{dt}\right\}=0,
\end{gathered}
$$

which has the unique solution $\mathrm{S}_{1}{ }^{*}\left(\mathrm{x}_{1}\right)=\mathrm{x}_{1}+\mathrm{k}^{\mathrm{D}}$. To see that this is a local maximum, note that the second-order condition for a maximum is satisfied:

$$
-\left(\mathrm{S}_{1}+\mathrm{g}-\mathrm{x}_{1}+\mathrm{k}^{\mathrm{P}}\right) \mathrm{r}_{1} *^{\prime \prime}-2 \mathrm{r}_{1} *^{\prime}\left(1+\mathrm{g}^{\prime}\right)+\left(1-\mathrm{r}_{1}^{*}\right) \mathrm{g}^{\prime \prime}<0 \text { at } \mathrm{S}_{1}=\mathrm{x}_{1}+\mathrm{k}^{\mathrm{D}} .
$$

This inequality follows from the facts that:

and

$$
\begin{aligned}
& 1-\mathrm{r}_{1}^{*}=\exp \left\{-\int_{\left[\underline{S}, \mathrm{~S}_{\mathrm{I}}\right]}\left(1+\mathrm{g}^{\prime}(\mathrm{t})\right) /(\mathrm{K}+\mathrm{g}(\mathrm{t})) \mathrm{dt}\right\}, \\
& \mathrm{r}_{1}{ }^{\prime}=\left[\left(\left(1+\mathrm{g}^{\prime}\right) /(\mathrm{K}+\mathrm{g})\right] \exp \left\{-\int_{\left[\underline{\mathrm{S}}, \mathrm{S}_{\mathrm{I}}\right]}\left(1+\mathrm{g}^{\prime}(\mathrm{t})\right) /(\mathrm{K}+\mathrm{g}(\mathrm{t})) \mathrm{dt}\right\},\right.
\end{aligned}
$$




$$
\mathrm{r}_{1}{ }^{\prime \prime}=\left\{\mathrm{d}\left[\left(1+\mathrm{g}^{\prime}\right) /(\mathrm{K}+\mathrm{g})\right] / \mathrm{dS}_{1}-\left[\left(1+\mathrm{g}^{\prime}\right) /(\mathrm{K}+\mathrm{g})\right]^{2}\right\} \exp \left\{-\int_{\left[\mathrm{S}, \mathrm{S}_{\mathrm{t}}\right]}\left(1+\mathrm{g}^{\prime}(\mathrm{t})\right) /(\mathrm{K}+\mathrm{g}(\mathrm{t})) \mathrm{dt}\right\} .
$$

Plugging these into the second-order condition above, evaluating the resulting expression at $\mathrm{S}_{1}=\mathrm{x}_{1}$ $+\mathrm{k}^{\mathrm{D}}$, collecting terms and simplifying implies that the second-order condition for a maximum holds at $\mathrm{S}_{1}=\mathrm{x}_{1}+\mathrm{k}^{\mathrm{D}}$ if and only if $-\left(1+\mathrm{g}^{\prime}\right) /(\mathrm{K}+\mathrm{g})<0$, which has been shown to hold.

If another maximum were to exist on the boundary (that is, at $\underline{\mathrm{S}}$ or $\overline{\mathrm{S}}$ ), there would have to be a local minimum between it and $\mathrm{S}_{1} *\left(\mathrm{x}_{1}\right)$, but no other interior stationary point exists, since $\mathrm{S}_{1} *\left(\mathrm{x}_{1}\right)$ is the unique interior solution to the first-order condition. Thus $\mathrm{S}_{1} *\left(\mathrm{x}_{1}\right)$ provides the global maximum to P's payoff.

Proof of (3-C). Substitution yields $\mathrm{b}_{1} *\left(\mathrm{~S}_{1} *\left(\mathrm{x}_{1}\right)\right)=\mathrm{S}_{1} *\left(\mathrm{x}_{1}\right)-\mathrm{k}^{\mathrm{D}}=\mathrm{x}_{1}+\mathrm{k}^{\mathrm{D}}-\mathrm{k}^{\mathrm{D}}=\mathrm{x}_{1}$ for $\mathrm{x}_{1} \in[\underline{\mathrm{x}}, \overline{\mathrm{x}}]$; thus the beliefs are correct in equilibrium. Moreover, the equilibrium strategies are robust to arbitrary out-of-equilibrium beliefs. QED

Proof of Proposition 4. From the definitions of $\hat{r}_{1}\left(x_{1}\right)$ and $\hat{r}_{0}\left(x_{1}\right)$, it is clear that $\hat{r}_{1}(\underline{x})=\hat{r}_{0}(\underline{x})$, and that $\hat{\mathrm{r}}_{1}\left(\mathrm{x}_{1}\right)<\hat{\mathrm{r}}_{0}\left(\mathrm{x}_{1}\right)$ for all $\mathrm{x}_{1} \in(\underline{\mathrm{x}}, \overline{\mathrm{x}}]$ if and only if

$$
\int_{\left[\underline{\mathrm{x}}, \mathrm{x}_{1}\right]}\left(1+\mathrm{g}^{\prime}\left(\mathrm{S}_{1} *(\mathrm{x})\right)\right) /\left(\mathrm{K}+\mathrm{g}\left(\mathrm{S}_{1} *(\mathrm{x})\right)\right) \mathrm{dx}<\int_{\left[\underline{\mathrm{x}}, \mathrm{x}_{1}\right]}(1 / \mathrm{K}) \mathrm{dx} \text { for all } \mathrm{x}_{1} \in(\underline{\mathrm{x}}, \overline{\mathrm{x}}] .
$$

We claim that $\left(1+\mathrm{g}^{\prime}\left(\mathrm{S}_{1} *(\mathrm{x})\right)\right) /\left(\mathrm{K}+\mathrm{g}\left(\mathrm{S}_{1} *(\mathrm{x})\right)\right)<1 / \mathrm{K}$ (or, equivalently, that $\left.\mathrm{g}^{\prime}\left(\mathrm{S}_{1} *(\mathrm{x})\right)<\mathrm{g}\left(\mathrm{S}_{1} *(\mathrm{x})\right) / \mathrm{K}\right)$ for all $\mathrm{x} \in[\underline{\mathrm{x}}, \overline{\mathrm{x}})$ when $\mathrm{F}(\bullet)$ is uniform, which implies that the inequality in the displayed equation above holds for all $\mathrm{x}_{1} \in(\underline{\mathrm{x}}, \overline{\mathrm{x}}]$.

Since $\mathrm{g}^{\prime}\left(\mathrm{S}_{1}\right)=\int\left[\partial \mathrm{h}\left(\mathrm{S}_{1} ; \mathrm{x}_{2}\right) / \partial \mathrm{S}_{1}-\mathrm{h}\left(\mathrm{S}_{1} ; \mathrm{x}_{2}\right) / \mathrm{K}\right] \exp \left\{-\left(\mathrm{S}_{1}-\underline{\mathrm{S}}\right) / \mathrm{K}\right\} \mathrm{f}\left(\mathrm{x}_{2}\right) \mathrm{dx} \mathrm{x}_{2}$, it follows that $\mathrm{g}^{\prime}\left(\mathrm{S}_{1} *(\mathrm{x})\right)<\mathrm{g}\left(\mathrm{S}_{1}^{*}(\mathrm{x})\right) / \mathrm{K}$ if and only if:

$$
\left.\mathrm{H}(\mathrm{x}) \equiv \int\left[\partial \mathrm{h}\left(\mathrm{S}_{1}^{*}(\mathrm{x}) ; \mathrm{x}_{2}\right) / \partial \mathrm{S}_{1}\right)-2 \mathrm{~h}\left(\mathrm{~S}_{1}^{*}(\mathrm{x}) ; \mathrm{x}_{2}\right) / \mathrm{K}\right] \exp \{-(\mathrm{x}-\underline{\mathrm{x}}) / \mathrm{K}\} \mathrm{f}\left(\mathrm{x}_{2}\right) \mathrm{dx} \mathrm{x}_{2}<0,
$$

where the integral is taken over $\mathrm{x}_{2} \in \mathrm{T}\left(\mathrm{S}_{1} *(\mathrm{x})\right)=[\mathrm{x}, \min \{\overline{\mathrm{x}}, \mathrm{x}+2 \mathrm{~K}\}]$. Note that $\mathrm{T}\left(\mathrm{S}_{1} *(\mathrm{x})\right)$ is nondegenerate whenever $\mathrm{S}_{1}{ }^{*}(\mathrm{x})<\overline{\mathrm{x}}+\mathrm{k}^{\mathrm{D}}$; that is, whenever $\mathrm{x}<\overline{\mathrm{x}}$. A sufficient condition for $\mathrm{H}(\mathrm{x})<$ 0 for all $\mathrm{x} \in[\underline{\mathrm{x}}, \overline{\mathrm{x}})$ is that $\mathrm{F}\left(\mathrm{x}_{2}\right)$ is the uniform distribution. To see this, substitute $\mathrm{f}\left(\mathrm{x}_{2}\right)=1 /(\overline{\mathrm{x}}-\underline{\mathrm{x}})$, integrate and simplify to obtain:

$$
\mathrm{H}(\mathrm{x})=\left[\exp \{-(\mathrm{x}-\underline{\mathrm{x}}) / \mathrm{K}\} / 2 \mathrm{~K}^{2}(\overline{\mathrm{x}}-\underline{\mathrm{x}})\right] \mathrm{Y}\left\{\mathrm{Y}^{2} / 3-\mathrm{YK} / 2-\mathrm{K}^{2}\right\} \text {, where } \mathrm{Y} \equiv \min \{\overline{\mathrm{x}}-\mathrm{x}, 2 \mathrm{~K}\} \text {. }
$$

The term in square brackets is positive, as is $\mathrm{Y}$ itself, so $\mathrm{H}(\mathrm{x})<0$ so long as $\mathrm{M}(\mathrm{Y}) \equiv \mathrm{Y}^{2} / 3-\mathrm{YK} / 2$ $\mathrm{K}^{2}<0$. Since $\mathrm{Y}=\min \{\overline{\mathrm{x}}-\mathrm{x}, 2 \mathrm{~K}\} \in(0,2 \mathrm{~K}]$ for $\mathrm{x} \in[\underline{\mathrm{x}}, \overline{\mathrm{x}})$, if we can show that $\mathrm{M}(\mathrm{y})<0$ for all $\mathrm{y}$ $\in[0,2 \mathrm{~K}]$, the proof will be complete. The function $\mathrm{M}(\bullet)$ is convex on $[0,2 \mathrm{~K}]$ with $\mathrm{M}(0)=-\mathrm{K}^{2}<$ 0 and $M(2 K)=-2 K^{2} / 3<0$. Since $M(\bullet)$ is convex, $M(t \times 0+(1-t) \times 2 K) \leq t M(0)+(1-t) M(2 K)<0$ for all $\mathrm{t} \in[0,1]$. Therefore $\mathrm{M}(\mathrm{y})<0$ for all $\mathrm{y} \in[0,2 \mathrm{~K}]$, and the claim is proved. QED

Proof of Proposition 5. First note that, for any given $\mathrm{x}_{1}, \hat{\pi}_{2}^{\mathrm{p}}\left(\mathrm{x}_{2} ; \mathrm{x}_{1}\right)$ is a continuous function of $\mathrm{x}_{2}$. (i) When $\mathrm{x}_{2} \in\left[\underline{\mathrm{x}}, \mathrm{x}_{1}\right], \mathrm{P}_{2}$ 's optimal demand is $\mathrm{S}_{2} *\left(\mathrm{x}_{2} ; \mathrm{S}_{1} *\left(\mathrm{x}_{1}\right)\right)=\mathrm{x}_{2}+\mathrm{k}^{\mathrm{D}}=\mathrm{S}_{0} *\left(\mathrm{x}_{2}\right) \leq \mathrm{S}_{1} *\left(\mathrm{x}_{1}\right)$, so the 
MFN does not bind, and $\hat{r}_{2}\left(x_{2} ; x_{1}\right)=\hat{r}_{0}\left(x_{2}\right)$. Thus, this part follows immediately by substitution.

(ii) When $\mathrm{x}_{2} \in\left(\mathrm{x}_{1}, \min \left\{\overline{\mathrm{x}}, \mathrm{x}_{1}+2 \mathrm{~K}\right\}\right], \mathrm{P}_{2}{ }^{\prime}$ s optimal demand is constrained by the MFN and $\mathrm{S}_{2} *\left(\mathrm{x}_{2}\right.$; $\left.\mathrm{S}_{1} *\left(\mathrm{x}_{1}\right)\right)=\left(\mathrm{x}_{2}+\mathrm{x}_{1}+2 \mathrm{k}^{\mathrm{D}}\right) / 2$ and $\mathrm{r}_{2}\left(\mathrm{x}_{2} ; \mathrm{x}_{1}\right)=1-\left\{\left[\mathrm{x}_{1}+2 \mathrm{~K}-\mathrm{x}_{2}\right] / 2 \mathrm{~K}\right\} \exp \left\{-\left(\mathrm{x}_{1}-\underline{\mathrm{x}}\right) / \mathrm{K}\right\}$. After substitution and simplification, $\hat{\pi}_{2}^{\mathrm{P}}\left(\mathrm{x}_{2} ; \mathrm{x}_{1}\right)=\mathrm{x}_{2}-\mathrm{K}^{\mathrm{P}}+\left[\left(\mathrm{x}_{1}+2 \mathrm{~K}-\mathrm{x}_{2}\right)^{2} / 4 \mathrm{~K}\right] \exp \left\{-\left(\mathrm{x}_{1}-\underline{\mathrm{x}}\right) / \mathrm{K}\right\}$, while $\hat{\pi}_{0}^{\mathrm{P}}\left(\mathrm{x}_{2}\right)=\mathrm{x}_{2}-\mathrm{k}^{\mathrm{P}}+\operatorname{Kexp}\left\{-\left(\mathrm{x}_{2}-\underline{\mathrm{x}}\right) / \mathrm{K}\right\}$. Let $\mathrm{z} \equiv \mathrm{x}_{1}+2 \mathrm{~K}-\mathrm{x}_{2}$. For $\mathrm{x}_{2} \in\left(\mathrm{x}_{1}, \min \left\{\overline{\mathrm{x}}, \mathrm{x}_{1}+2 \mathrm{~K}\right\}\right], \mathrm{z} \in$ $[0,2 \mathrm{~K})$. Then $\hat{\pi}_{2}^{\mathrm{P}}\left(\mathrm{x}_{2} ; \mathrm{x}_{1}\right)<\hat{\pi}_{0}^{\mathrm{P}}\left(\mathrm{x}_{2}\right)$ for $\mathrm{x}_{2} \in\left(\mathrm{x}_{1}, \min \left\{\overline{\mathrm{x}}, \mathrm{x}_{1}+2 \mathrm{~K}\right\}\right]$ if and only if $\mathrm{m}(\mathrm{z}) \equiv(\mathrm{ez} / 2 \mathrm{~K})^{2}-$ $\exp \{\mathrm{z} / \mathrm{k}\}<0$ for all $\mathrm{z} \in[0,2 \mathrm{~K})$, which is true. On the interval $[0,2 \mathrm{~K}], \mathrm{m}(\mathrm{z})$ starts out negative at $\mathrm{m}(0)=-1$, and is decreasing and convex. It reaches an interior minimum and is thereafter increasing and, eventually, concave, reaching another stationary point, a maximum, at $\mathrm{z}=2 \mathrm{~K}$, where $\mathrm{m}(2 \mathrm{~K})=0$. Thus, $\mathrm{m}(\mathrm{z})<0$ for all $\mathrm{z} \in[0,2 \mathrm{~K})$.

(iii) Finally, consider $\mathrm{x}_{2} \in\left(\min \left\{\overline{\mathrm{x}}, \mathrm{x}_{1}+2 \mathrm{~K}\right\}, \overline{\mathrm{x}}\right]$. For these values of $\mathrm{x}_{2}, \mathrm{P}_{2}$ goes to trial for sure since $\hat{\mathrm{r}}_{2}\left(\mathrm{x}_{2} ; \mathrm{x}_{1}\right)=1$, and thus $\hat{\pi}_{2}^{\mathrm{P}}\left(\mathrm{x}_{2} ; \mathrm{x}_{1}\right)=\mathrm{x}_{2}-\mathrm{k}^{\mathrm{P}}$. On the other hand, $\hat{\pi}_{0}^{\mathrm{P}}\left(\mathrm{x}_{2}\right)=\mathrm{x}_{2}-\mathrm{k}^{\mathrm{P}}+\operatorname{Kexp}\left\{-\left(\mathrm{x}_{2}-\underline{\mathrm{x}}\right) / \mathrm{K}\right\}>$ $\mathrm{x}_{2}-\mathrm{k}^{\mathrm{P}}$. QED

Proof of Proposition 6. We argue that when $\mathrm{F}(\bullet)$ is the uniform distribution, expected trial costs are lower in both the first and second periods with an MFN. We have already shown that a uniform distribution for $\mathrm{x}_{1}$ is sufficient to guarantee that $\hat{\mathrm{r}}_{1}\left(\mathrm{x}_{1}\right)<\hat{\mathrm{r}}_{0}\left(\mathrm{x}_{1}\right)$ for all $\mathrm{x}_{1} \in(\underline{\mathrm{x}}, \overline{\mathrm{x}}]$, while $\hat{\mathrm{r}}_{1}(\underline{\mathrm{x}})=\hat{\mathrm{r}}_{0}(\underline{\mathrm{x}})$. Since expected trial costs in the first period are simply $\operatorname{KE}\left\{\hat{r}_{1}\left(\mathrm{x}_{1}\right)\right\}$ with an MFN and $\operatorname{KE}\left\{\hat{\mathrm{r}}_{0}\left(\mathrm{x}_{1}\right)\right\}$ without an MFN (where the expectation is taken over $\mathrm{x}_{1}$ ), it is clear that first-period expected trial costs are lower with an MFN.

It is perhaps more surprising that expected trial costs in the second period are also lower with an MFN when $\mathrm{x}_{2}$ is uniformly distributed. Although any given demand $\mathrm{S}_{2}$ is rejected with a higher probability when the MFN is binding, $\mathrm{P}_{2}{ }^{\prime} \mathrm{s}$ demand is reduced when the MFN is binding. The composition of these two effects means that $\hat{r}_{2}\left(x_{2} ; x_{1}\right)$ may be more, or less, than $\hat{r}_{0}\left(x_{2}\right)$ for $x_{2} \in$ $\left[\mathrm{x}_{1}, \overline{\mathrm{x}}\right]$. These expressions are the same when the MFN does not bind; that is, when $\mathrm{x}_{2} \in\left[\underline{\mathrm{x}}, \mathrm{x}_{1}\right]$. We fix a value of $x_{1}$ and argue that, if $x_{2}$ is distributed uniformly, then the expected trial costs for the second period are lower under an MFN. Since this will be shown to be true for all values of $\mathrm{x}_{1}$ (except $\mathrm{x}_{1}=\overline{\mathrm{x}}$, in which case the MFN never binds for any $\mathrm{x}_{2}$ ), the ex ante expected trial costs for the second period are lower under an MFN.

Recall that $\hat{r}_{2}\left(\mathrm{x}_{2} ; \mathrm{x}_{1}\right)=1-\left\{\left[\mathrm{x}_{1}+2 \mathrm{~K}-\mathrm{x}_{2}\right] / 2 \mathrm{~K}\right\} \exp \left\{-\left(\mathrm{x}_{1}-\underline{\mathrm{x}}\right) / \mathrm{K}\right\}$ for $\mathrm{x}_{2} \in\left[\mathrm{x}_{1}, \min \left\{\overline{\mathrm{x}}, \mathrm{x}_{1}+2 \mathrm{~K}\right\}\right]$, while $\hat{r}_{2}\left(\mathrm{x}_{2} ; \mathrm{x}_{1}\right)=1$ for $\mathrm{x}_{2} \in\left(\min \left\{\overline{\mathrm{x}}, \mathrm{x}_{1}+2 \mathrm{~K}\right\}, \overline{\mathrm{x}}\right]$. Without an MFN, $\hat{\mathrm{r}}_{0}\left(\mathrm{x}_{2}\right)=1-\exp \left\{-\left(\mathrm{x}_{2}-\underline{\mathrm{x}}\right) / \mathrm{K}\right\}$ for all $\mathrm{x}_{2} \in\left[\mathrm{x}_{1}, \overline{\mathrm{x}}\right]$. Thus, multiplying by the cost per trial and taking the expectation over $\mathrm{x}_{2} \in$ $\left[\mathrm{x}_{1}, \overline{\mathrm{x}}\right]$ (where the probability of a trial differs with and without an MFN) yields:

$$
\begin{aligned}
\mathrm{ETC}_{2}\left(\mathrm{x}_{1}\right)-\mathrm{ETC}_{0}=\mathrm{K} \int_{\left[\mathrm{x}_{1}, \overline{\mathrm{x}}\right]} \hat{\mathrm{r}}_{2}\left(\mathrm{x}_{2} ; \mathrm{x}_{1}\right) \mathrm{f}\left(\mathrm{x}_{2}\right) \mathrm{dx} \mathrm{x}_{2}-\mathrm{K} \int_{\left[\mathrm{x}_{1}, \overline{\mathrm{x}}\right]} \hat{\mathrm{r}}_{0}\left(\mathrm{x}_{2}\right) \mathrm{f}\left(\mathrm{x}_{2}\right) \mathrm{dx} \mathrm{x}_{2} \\
=\mathrm{K} \int_{\left[\mathrm{x}_{1}, \overline{\mathrm{x}}\right]} \exp \left\{-\left(\mathrm{x}_{2}-\underline{\mathrm{x}}\right) / \mathrm{K}\right\} \mathrm{f}\left(\mathrm{x}_{2}\right) \mathrm{dx} \mathrm{x}_{2} \\
\quad-\operatorname{Kexp}\left\{-\left(\mathrm{x}_{1}-\underline{\mathrm{x}}\right) / \mathrm{K}\right\} \int_{\left[\mathrm{x}_{1}, \min \left\{\overline{\mathrm{x}}, \mathrm{x}_{1}+2 \mathrm{~K}\right\}\right]}\left[\left(\mathrm{x}_{1}+2 \mathrm{~K}-\mathrm{x}_{2}\right) / 2 \mathrm{~K}\right] \mathrm{f}\left(\mathrm{x}_{2}\right) \mathrm{d} \mathrm{x}_{2} .
\end{aligned}
$$


Clearly, $\mathrm{ETC}_{2}(\overline{\mathrm{x}})-\mathrm{ETC}_{0}=0$, since the domains of integration are then degenerate. Thus, consider values of $\mathrm{x}_{1}<\overline{\mathrm{x}}$ in the remainder of the proof. Substitute $\mathrm{f}\left(\mathrm{x}_{2}\right)=1 /(\overline{\mathrm{x}}-\underline{\mathrm{x}})$, integrate and simplify to obtain:

$\mathrm{ETC}_{2}\left(\mathrm{x}_{1}\right)-\mathrm{ETC}_{0}=[\mathrm{K} /(\overline{\mathrm{x}}-\underline{\mathrm{x}})] \exp \left\{-\left(\mathrm{x}_{1}-\underline{\mathrm{x}}\right) / \mathrm{K}\right\}$

$$
\times\left[\mathrm{K}\left(1-\exp \left\{-\left(\overline{\mathrm{x}}-\mathrm{x}_{1}\right) / \mathrm{K}\right\}\right)-\left(\mathrm{Z}-\mathrm{x}_{1}\right)\left(\mathrm{x}_{1}+4 \mathrm{~K}-\mathrm{Z}\right) / 4 \mathrm{~K}\right],
$$

where $\mathrm{Z}=\min \left\{\overline{\mathrm{x}}, \mathrm{x}_{1}+2 \mathrm{~K}\right\}$. There are two cases to consider.

Case 1. Assume that $x_{1}+2 K<\bar{x}$, so $Z=x_{1}+2 K$. Substituting and simplifying yields

$$
\mathrm{ETC}_{2}\left(\mathrm{x}_{1}\right)-\mathrm{ETC}_{0}=[\mathrm{K} /(\overline{\mathrm{x}}-\underline{\mathrm{x}})] \exp \left\{-\left(\mathrm{x}_{1}-\underline{\mathrm{x}}\right) / \mathrm{K}\right\}\left[\mathrm{K}\left(1-\exp \left\{-\left(\overline{\mathrm{x}}-\mathrm{x}_{1}\right) / \mathrm{K}\right\}\right)-\mathrm{K}\right],
$$

which is clearly negative. So $\operatorname{ETC}_{2}\left(\mathrm{x}_{1}\right)-\mathrm{ETC}_{0}<0$ for all $\mathrm{x}_{1}<\overline{\mathrm{x}}-2 \mathrm{~K}$.

Case 2. Assume that $\mathrm{x}_{1}+2 \mathrm{~K} \geq \overline{\mathrm{x}}$, so $\mathrm{Z}=\overline{\mathrm{x}}$. Substituting and simplifying yields

$$
\begin{aligned}
\mathrm{ETC}_{2}\left(\mathrm{x}_{1}\right)-\mathrm{ETC}_{0} & =[\mathrm{K} /(\overline{\mathrm{x}}-\underline{\mathrm{x}})] \exp \left\{-\left(\mathrm{x}_{1}-\underline{\mathrm{x}}\right) / \mathrm{K}\right\} \\
\times & {\left[\mathrm{K}\left(1-\exp \left\{-\left(\overline{\mathrm{x}}-\mathrm{x}_{1}\right) / \mathrm{K}\right\}\right)-\left(\overline{\mathrm{x}}-\mathrm{x}_{1}\right)\left(\mathrm{x}_{1}+4 \mathrm{~K}-\overline{\mathrm{x}}\right) / 4 \mathrm{~K}\right] . }
\end{aligned}
$$

Let $\mathrm{v} \equiv \overline{\mathrm{x}}-\mathrm{x}_{1}$. Then $\operatorname{sgn}\left\{\mathrm{ETC}_{2}\left(\mathrm{x}_{1}\right)-\mathrm{ETC}_{0}\right\}=\operatorname{sgn}\{[\mathrm{K}(1-\exp \{-\mathrm{v} / \mathrm{K}\})-\mathrm{v}(4 \mathrm{~K}-\mathrm{v}) / 4 \mathrm{~K}]\}$. Since $\mathrm{x}_{1}$ $\in[\overline{\mathrm{x}}-2 \mathrm{~K}, \overline{\mathrm{x}})$ implies that $\mathrm{v} \in(0,2 \mathrm{~K}]$, we need only verify that $\mathrm{K}(1-\exp \{-\mathrm{v} / \mathrm{K}\})-\mathrm{v}(4 \mathrm{~K}-\mathrm{v}) / 4 \mathrm{~K}<$ 0 for all $\mathrm{v} \in(0,2 \mathrm{~K}]$. This inequality holds for the specified values of $\mathrm{v}$. Thus, $\mathrm{ETC}_{2}\left(\mathrm{x}_{1}\right)-\mathrm{ETC}_{0}<$ 0 for $\mathrm{x}_{1} \in[\overline{\mathrm{x}}-2 \mathrm{~K}, \overline{\mathrm{x}})$, as claimed. QED 


\section{References}

Aghion, Philippe and Patrick Bolton (1987). "Contracts as a Barrier to Entry,” American Economic Review, 77, 388-401.

Bulow, Jeremy (1982). "Durable-Goods Monopolists," Journal of Political Economy 90, 314-32.

Butz, David A. (1990). "Durable-Good Monopoly and Best-Price Provisions," American Economic Review 80, 1062-1076.

Choi, Jay P. (1995). "Optimal Tariffs and the Choice of Technology: Discriminatory Tariffs vs. the 'Most Favored Nation' Clause," Journal of International Economics 38, 143-160.

Coase, Ronald H. (1972). “Durability and Monopoly,” Journal of Law and Economics 15, 143-149.

Cooper, Thomas E. and Timothy L. Fries (1991). "The Most Favored Nation Pricing Policy and Negotiated Prices," International Journal of Industrial Organization 9, 209-223.

Cooter, Robert and Ulen, Thomas (2000). Law and Economics, $3^{\text {rd }}$ Edition. Reading, MA: Addison Wesley Longman, Inc.

Daughety, Andrew F. and Jennifer F. Reinganum (1999). "Hush Money," RAND Journal of Economics 30, 661-678.

Daughety, Andrew F. and Jennifer F. Reinganum (2002). "Informational Externalities in Settlement Bargaining: Confidentiality and Correlated Culpability," RAND Journal of Economics (forthcoming).

LaFrance, Arthur B. (2000). “Tobacco Litigation: Smoke, Mirrors and Public Policy," American Journal of Law and Medicine 26, 187-203.

Levy, Stephan M. (2000). "Best Price Guarantees as a Quality Signal," Working Paper (Nathan Associates, Inc., Arlington, VA).

Marx, Leslie M. and Greg Shaffer (2001). "Opportunism and Nondiscrimination Clauses," University of Rochester Working Paper.

McAfee, R. Preston and Marius Schwartz (1994). "Opportunism in Multilateral Vertical Contracting: Nondiscrimination, Exclusivity, and Uniformity," American Economic Review $84,210-230$.

Neilson, William S. and Harold Winter (1994). "Enhanced Bargaining Power with Most-FavoredCustomer Pricing," Economics Letters 44, 61-66. 
Rea, Samuel A., Jr. (1998). "Penalty Doctrine in Contract Law," in The New Palgrave Dictionary of Economics and the Law, Ed. by P. Newman. New York: Stockton Press.

Reinganum, Jennifer F. and Louis L. Wilde (1986). "Settlement, Litigation and the Allocation of Litigation Costs," RAND Journal of Economics 17, 557-566.

Sage, Michael J. and Marc Bennett (2001). "Most-Favored-Nations Clauses: Do They Help Reach Agreements or Just Create Problems?" The Bankruptcy Strategist 19, 1-6.

Schlosser, Jennifer (2001). "The D.C. Circuit Review August 1999 - July 2000," George Washington Law Review, 69, 511-520.

Spier, Kathryn E. (forthcoming). "The Use of 'Most-Favored-Nation' Clauses in Settlement of Litigation," RAND Journal of Economics

Spier, Kathryn E. (2002). "Tied to the Mast: Most-Favored-Nation Clauses in Settlement Contracts," Working Paper, Department of Management and Strategy, Northwestern University.

Viscusi, W. Kip (2002). Smoke-Filled Rooms: A Postmortem on the Tobacco Deal. Chicago: University of Chicago Press. 